\title{
MARTX Toxin in the Zoonotic Serovar of Vibrio vulnificus Triggers an Early Cytokine Storm in Mice
}

\author{
Celia Murciano ${ }^{1 *}$, Chung-Te Lee ${ }^{2}$, Ana Fernández-Bravo ${ }^{1 \dagger}$, Tsung-Han Hsieh ${ }^{2}$, \\ Belén Fouz ${ }^{1}$, Lien-I Hor ${ }^{2,3}$ and Carmen Amaro ${ }^{1 *}$
}

${ }^{1}$ Departamento de Microbiología y Ecología \& Estructura de Recerca Interdisciplinar en Biotecnologia i Biomedicina, Universitat de València, Valencia, Spain, ${ }^{2}$ Department of Microbiology \& Immunology \& College of Medicine, National Cheng Kung University, Tainan, Taiwan, ${ }^{3}$ Institute of Basic Medical Sciences, College of Medicine, National Cheng Kung University, Tainan, Taiwan

\section{OPEN ACCESS}

Edited by:

Matthew S. Francis,

Umeå University, Sweden

Reviewed by:

Charles Martin Dozois,

Institut National de la Recherche

Scientifique, Canada

Salvador Almagro-Moreno,

University of Central Florida College of

Medicine, United States

Karla Satchell,

Northwestern University, United States

*Correspondence:

Celia Murciano

celia.murciano@uv.es

Carmen Amaro

carmen.amaro@uv.es

${ }^{\dagger}$ Present Address:

Ana Fernández-Bravo,

Unidad de Microbiología,

Departamento de Ciencias Médicas Básicas, Universidad Rovira i Virgili,

Reus, Spain

Received: 09 May 2017 Accepted: 05 July 2017

Published: 20 July 2017

Citation:

Murciano C, Lee C-T,

Fernández-Bravo A, Hsieh T-H,

Fouz B, Hor L-I and Amaro C (2017)

MARTX Toxin in the Zoonotic Serovar

of Vibrio vulnificus Triggers an Early

Cytokine Storm in Mice.

Front. Cell. Infect. Microbiol. 7:332.

doi: 10.3389/fcimb.2017.00332
Vibrio vulnificus biotype 2-serovar $\mathrm{E}$ is a zoonotic clonal complex that can cause death by sepsis in humans and fish. Unlike other biotypes, Bt2 produces a unique type of MARTXVv (Multifunctional-Autoprocessive-Repeats-in-Toxin; RtXA1 $_{3}$ ), which is encoded by a gene duplicated in the pVvBt2 plasmid and chromosome II. In this work, we analyzed the activity of this toxin and its role in human sepsis by performing in vitro, ex vivo, and in vivo assays. First, we demonstrated that the ACD domain, present exclusively in this toxin variant, effectively has an actin-cross-linking activity. Second, we determined that the whole toxin caused death of human endotheliocytes and monocytes by lysis and apoptosis, respectively. Finally, we tested the hypothesis that RtxA1 3 contributes to human death caused by this zoonotic serovar by triggering an early cytokine storm in blood. To this end, we used a Bt2-SerE strain (R99) together with its $r$ $X A 1_{3}$ deficient mutant, and a Bt1 strain (YJ016) producing RtXA1 1 (the most studied MARTX $_{V V}$ ) together with its $r t \times A 1_{1}$ deficient mutant, as controls. Our results showed that RtXA1 $1_{3}$ was essential for virulence, as $R 99 \Delta \Delta r t \times A 1_{3}$ was completely avirulent in our murine model of infection, and that R99, but not strain YJ016, induced an early, strong and dysregulated immune response involving the up-regulation of a high number of genes. This dysregulated immune response was directly linked to RtxA13. Based on these results and those obtained ex vivo (human blood), we propose a model of infection for the zoonotic serovar of $V$. vulnificus, in which $\mathrm{RtxA} 1_{3}$ would act as a sepsis-inducing toxin.

Keywords: Vibrio, V. vulnificus, MARTX, sepsis, infection, gene expression, qPCR array

\section{INTRODUCTION}

Vibrio vulnificus is an autochthonous inhabitant of marine and estuarine waters located in tropical, subtropical, and temperate ecosystems (Oliver, 2015). Currently, the species is expanding to cooler areas such as, the Baltic Sea coast due to global warming (Baker-Austin et al., 2012). V. vulnificus switches between free-swimming and sessile life-forms, both establishing particular relationships with filtering organisms (mainly oysters) and fish (mainly eels), its animal reservoirs in water (Oliver, 2015). V. vulnificus was defined as a bacterial species in 1976 and was later split into three biotypes (Bts) on the basis of differences in phenotypic and genotypic traits as well as host range (Tison et al., 1982; Bisharat et al., 1999). 
The diseases caused by Vibrio species are known as vibrioses. There are two main forms of human vibriosis related to the transmission route; contact (type I) or ingestion (type II). In type I, the pathogen causes severe tissue necrosis after contact of a wound with seawater or fish that can lead to debridement/amputation or even secondary septicaemia (Strom and Paranjpye, 2000; Jones and Oliver, 2009). Since people that suffer human vibriosis type I are usually swimmers, bathers and fishers, this pathogen is sometime known as the "marine flesheating bacterium." In type II, the pathogen causes gastroenteritis or primary septicemia after ingestion of raw seafood. The common characteristic to both vibrioses is that they can lead to sepsis with a probability of death strongly dependent on iron levels in patient's blood (Feldhusen, 2000; Jones and Oliver, 2009; Horseman and Surani, 2011), being $>50 \%$ in patients with hemochromatosis or other iron overload conditions (Horseman and Surani, 2011; Arezes et al., 2015). Fish vibriosis is a haemorrhagic septicaemia produced by contact with water or fish (carrier or diseased) without a relationship with high iron levels in blood (Amaro et al., 2015). The common feature of fish and human vibrioses is that the pathogen invades the blood causing sepsis. Regarding Bts, all three can cause human vibriosis but only Bt2 is also able to cause fish vibriosis, an ability that relies on a plasmid which encodes a resistance system to the fish innate immunity (Amaro and Biosca, 1996; Lee et al., 2008; Valiente et al., 2008b; Amaro et al., 2015). Further, among Bt2 strains, only those belonging to clonal complex Bt2-SerE (serovar) are recognized as being truly zoonotic (Amaro and Biosca, 1996; Sanjuán et al., 2011).

Among all the $V$. vulnificus virulence factors, the RtxA1 toxin seems to be the most relevant, as it is the one present in the majority of clinical strains (Satchell, 2011, 2015; Lee et al., 2013; Kim et al., 2015). In the case of human vibriosis, RtxA1 was proposed to be involved in innate immune evasion in subcutaneously infected mice (model for type I vibriosis; Lo et al., 2011) as well as in intestinal epithelium destruction plus blood invasion in intragastrically infected mice (model for type II; Kim et al., 2008; Jeong and Satchell, 2012). In the latter model, it seems that the major hemolysin produced by the three Bts of $V$. vulnificus, VvhA, could have an additive effect on RtxA1 (Jeong and Satchell, 2012). In the case of fish vibriosis, RtxA1 is involved in both defense against innate immune cells (phagocytosis experiments with primary cultures of eel's neutrophils) and animal death (virulence experiments in eels infected by intraperitoneal [i.p.] injection or immersion) (Callol et al., 2015a,b).

V. vulnificus RtxA1, or MARTX $\mathrm{Vv}_{\mathrm{v}}$, belongs to the subfamily of Multifunctional Autoprocessing Repeats-in-toxins (Fullner Satchell, 2007; Satchell, 2011, 2015). MARTX toxins present two common external modules containing the repeat sequences, together with a variable internal module containing a unique combination of functional domains responsible for the toxic action. The toxin is secreted after bacterium-cell contact and it associates to the eukaryotic cell membrane where the external modules form a pore for translocation of the internal module to the cytoplasm. Later, the toxin autoprocesses and the domains are liberated into the cytoplasm. Seven types of MARTX $\mathrm{Vv}_{\mathrm{v}}$ and nine functional domains have been described so far (Satchell,
2015). The molecular function of eight out of these nine domains has been demonstrated by Dr. Satchell's laboratory (Antic et al., 2015; Dolores et al., 2015; Kim et al., 2015; Satchell, 2015; Agarwal et al., 2015a,b) (Figure 1). All MARTX $\mathrm{Vv}_{\mathrm{V}}$ seem to act as cytolysins in vitro but differ in the mechanism of cell destruction, which probably relys on the precise domain combination (Satchell, 2015). With the exception of Bt2, there is no relationship between RtxA1 type and Bts. Figure 1 shows the two main MARTX $\mathrm{Vv}_{\mathrm{v}}$ types. RtxA1 1 (or MARTX type I) is present in the most virulent Bt1 strains and its mode of action has been extensively studied (Lee et al., 2007; Liu et al., 2007; Kim et al., 2008, 2015; Kwak et al., 2011; Lo et al., 2011; Jeong and Satchell, 2012; Satchell, 2015). In contrast, $\mathrm{RtxA}_{3}$ (or MARTX type III) is still uncharacterized. Interestingly, $r t x \mathrm{~A}_{3}$ is duplicated in the $\mathrm{pVvBt} 2$ plasmid and the chromosome II of Bt2 strains.

The present work is focused on $\mathrm{RtxAl}_{3}$ and its hypothetical role in vivo as a virulence factor involved in both human and fish sepsis. Our hypothesis is that once the bacterium arrives in blood, and only if it is able to resist the bactericidal/bacteriostatic action of serum, the bacterium multiplies, liberates the toxin after its interaction with blood cells, and triggers a cytokine (CK) storm that could be fatal. This hypothesis is based on the results obtained in the eel; fish i.p.-infected with mutants deficient in both copies of the toxin were colonized internally and externally by the mutant but they the eels did not develop vibriosis (Lee et al., 2013). Further, there was no statistical differences in colonization index of internal organs between wild-type and mutant strains (Lee et al., 2013), and bacterial numbers were far below those characteristic for other fish pathogenic Vibrio spp. (i.e., V. anguillarum).

To demonstrate this hypothesis, we selected the Bt2-SerE wild-type strain CECT 4999 (R99) and its derivative mutant R99 $\Delta \Delta r t x A 1_{3}$, which lacks the two copies of $r \operatorname{txA} 1_{3}$, and generated three new mutants, one deficient in the ACD-domain (the only uncharacterized domain in $V$. vulnificus) (R99 $\triangle \triangle A C D)$ in $v v h A(\mathrm{R} 99 \Delta v v h A)$ and in both toxins (R99 $\left.\Delta \Delta r t x A 1_{3} \Delta v v h A\right)$. We included in the study strain YJ016, a Bt1 human isolate that produces $\mathrm{RtxA}_{1}$ (Bt1-RtxA1 $1_{1}$; Chen et al., 2003) as representative of the most virulent lineage (Cohen et al., 2007; Sanjuán et al., 2011), as well as its derivative mutant YJ016 $\Delta r t x A 1_{1}$ for comparative purposes. The strains were used in the following assays: (i) in vitro assays to determine the molecular action of the ACD domain and the type of cell death associated to RtxA1 3 ; (ii) ex vivo assays to compare growth in human blood/serum of Bt1-RtxA $1_{1}$ and Bt2 strains as well as to follow the transcription of $r t x A 1_{1}, r t x A 1_{3}$, and $v v h A$; and (iii) in vivo assays in an animal model of sepsis, in which we determined the virulence degree of the wild-type strain vs. each one of the mutants and followed the transcription in blood of 84 host immune-related genes.

\section{MATERIALS AND METHODS}

\section{Bacterial Strains, Plasmids, and Growth Conditions}

The bacterial strains and their characteristics are listed in Table 1. Bacteria were routinely grown on Tryptone Soy agar 


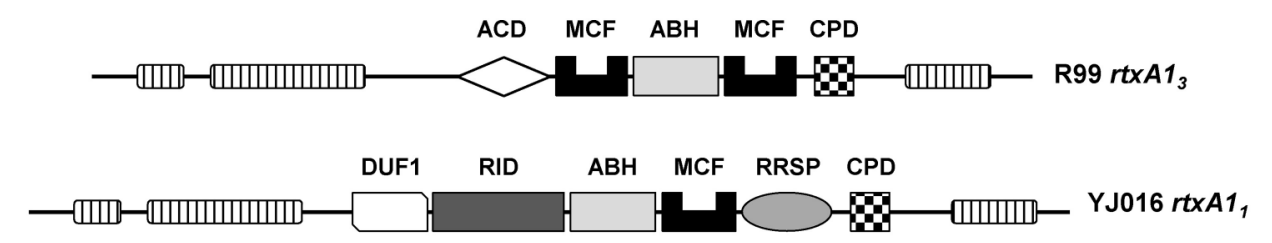

DOMAIN

FUNCTION

CPD: cysteine protease domain

Common to all MARTX. Responsible for domain release into the cell cytoplasm (Satchell, 2015)

DUF1: Domain of unkown function 1

Has effects on MAPK signaling through its binding to prohibitin-1 (Kim et al., 2015)

RID: Rho-GTPase inactivation domain

ABH: alpha-beta hydrolase

Induces actin depolymerization by inactivating Rho and CDC42 (Dolores et al., 2015)

MCF: Makes Caterpillars Floppy-like

An esterase/lipase that blocks autophagy and endosomal trafficking (Agarwal et al., 2015a)

RRSP: Ras/Rap1-specific protease

A cysteine autoprotease; induces the intrinsic pathway of apoptosis (Agarwal et al., 2015b)

ACD: Actin cross-linking domain

Produces loss of p-ERK resulting in cell rounding and inhibition of cell proliferation (Antic et al., 2015)

Induces actin polymerization that results in phagocytosis inhibition (Dolores et al., 2015)

FIGURE 1 | Schematic representation of type III and type I MARTX toxins, and function of each domain.

TABLE 1 | Strains used in this study.

\begin{tabular}{|c|c|c|}
\hline Designation & Description & Isolation source/References \\
\hline \multicolumn{3}{|l|}{ V. vulnificus } \\
\hline CECT 4999* (R99) & Biotype 2, serovar E (Bt2-SerE) & Diseased eel (Spain) (Lee et al., 2008) \\
\hline YJ016 & Biotype1 (Bt1-RtxA11) & Taiwan (1993) (Chen et al., 2003) \\
\hline $\mathrm{R} 99 \Delta \Delta r \mathrm{t} \times \mathrm{A}_{3}$ & CECT4999 rtxA13-defective mutant. Lacks both plasmidic and chromosomic copies & Lee et al., 2013 \\
\hline$R 99 \Delta v v h A$ & CECT4999 vvhA-defective mutant & This study \\
\hline $\mathrm{R} 99 \Delta \Delta \mathrm{ACD}$ & CECT4999 ACD domain-defective mutant & This study \\
\hline$R 99 \Delta \Delta r t \times A 1_{3} \Delta v v h A$ & CECT4999 rtxA1 3 and $v v h A$-defective mutant & This study \\
\hline YJ016 $\Delta r t \times A 1_{1}$ & YJ016 rtxA1 1-defective mutant & Lo et al., 2011 \\
\hline \multicolumn{3}{|l|}{ E. coli } \\
\hline $\mathrm{DH} 5 \alpha$ & SupE44 lacU169 ( $\varphi 80$ lacZM15)hsdR17 recA1 endA1 gyrA96 thi-1 relA1 & Hor et al., 2000 \\
\hline S17-1גpir & 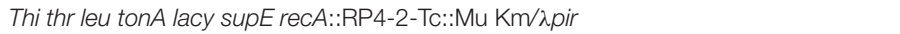 & Hanahan, 1983 \\
\hline
\end{tabular}

${ }^{\star}$ CECT 4999 (Spanish Type Culture Collection or CECT). ${ }^{\star \star}$ YJ016 [Dr. L-I Hor collection; originally isolated in the National Cheng-Kung University Hospital (Taiwan)].

supplemented with $0.5 \% \mathrm{NaCl}$ (TSA-1) at $37^{\circ} \mathrm{C}$ for $24 \mathrm{~h}$. Prior to mouse infection, the colony morphology on TSA-1 was checked to confirm its opaque morphology ( $V$. vulnificus shifts between opaque (capsulated) and translucent (acapsulated) morphotypes, as acapsulated cells are avirulent for mice (Simpson et al., 1987). All strains were stored in LB-1 plus glycerol (17\%) at $-80^{\circ} \mathrm{C}$.

The inoculum for ex vivo and in vivo assays was prepared as follows: one opaque colony was seeded in LB-1 (Luria-Bertani broth, $1 \% \mathrm{NaCl}$ ) and bacteria were incubated at $37^{\circ} \mathrm{C}$ with shaking $(100 \mathrm{rpm})$ up to mid-exponential growth phase. These bacterial cells were immediately used.

\section{Generation of the R99 $\Delta \Delta A C D, R 99 \Delta v v h A$, and $R 99 \Delta \Delta r t \times A 1_{3} \Delta v v h A$ Mutants}

All mutants were generated by in vivo allelic exchange as described previously (Shao and Hor, 2000). Briefly, to generate R99 $\Delta v v h A$ and R99 $\Delta \Delta r t x A 1_{3} \Delta v v h A$ mutants, DNA fragments from the $v v h A$ down- and up-stream regions were amplified with the primer pairs vvhA-1/vvhA-2 and vvhA-3/vvhA-4 (Supplementary Table 1), respectively. Both fragments were sequentially cloned into pGEMT $^{\circledR}$-easy vector (Promega) and then transformed into $\mathrm{DH} 5 \alpha$ to generate a recombinant fragment containing a $1,380 \mathrm{bp}$-deletion within $v v h A$. This recombinant fragment was removed from the pGEMT $^{\circledR}$-easy vector by enzymatic digestion at the two XmnI sites, and cloned into the suicide vector pCVD442. The recombinant suicide plasmid was

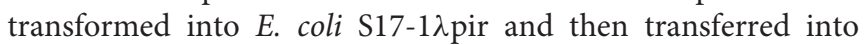
R99 or R99 $\Delta r t x A 1_{3}$ by conjugation to generate the mutants by allelic exchange. Similarly, to construct the R99 $\triangle A C D$ derivative, DNA fragments from the ACD down- and upstream regions were amplified with the primer pairs gp018/gp019 and gp020/gp021 (Supplementary Table 1), respectively, and then cloned into pUC19 between SacI and XbaI sites. This recombinant fragment, containing a 1,392-bp deletion in ACD, was removed by $\mathrm{SacI}$ and $\mathrm{XbaI}$ enzymatic digestion and then cloned into pCVD442. The resultant recombinant vector was 
transformed into $E$. coli S17-1 $\lambda$ pir and subsequently transferred into R99 by conjugation to generate the mutant by allelic exchange. All mutants were confirmed by PCR and sequence determination.

\section{In vitro Experiments}

\section{Cell Lines, Growth Conditions, and In vitro Infection}

The cell lines, THP-1 (human peripheral blood monocytes, ATCC reference number TIB-202) and ECV304 (human vascular endothelial cells, ATCC reference number CRL-1998) were obtained from the Cell Culture facility of the University of Valencia (Spain). THP-1 cells were maintained as suspension cells in Roswell Park Memorial Institute Medium (RPMI-1640, Biowest Europe) supplemented with 10\% FBS (fetal bovine serum, Biowest Europe) plus 1\% P/S solution (penicillinstreptomycin stock, Biowest Europe), and ECV304 cells were maintained as adherent cells in DMEM (Dulbecco's Modified Eagle's Medium) supplemented with $10 \%$ FBS plus $1 \% \mathrm{P} / \mathrm{S}$, in both cases at $37^{\circ} \mathrm{C}$ and $5 \% \mathrm{CO}_{2}$. Three hours or $24 \mathrm{~h}$ prior to infection, respectively, cells were seeded in tissue culture plates (5 $\times 10^{5}$ cells $\mathrm{mL}^{-1}$ ) containing serum and antibiotic-free DMEM (serum-starvation conditions). Cells were then infected with washed bacteria from exponential cultures in serum-free DMEM at different MOIs (multiplicity of infection; bacteria:human cell).

\section{Cell damage assay}

Supernatants from infected ECV304 were harvested and cell damage induction was determined by lactate dehydrogenase (LDH) release using the Cytox 96 Non-Radioactive Cytotoxicity Assay kit (Promega) according to manufacturer's instructions. A recombinant bovine LDH (Sigma-Aldrich) was used to generate a standard curve and sample values were extrapolated from the curve.

\section{Detection of Actin Polymerization by Western Blotting} Infected THP-1 and ECV304 cells were lysed using a modified RIPA lysis buffer (50 mM Tris-HCl, pH 7.4, $150 \mathrm{mM} \mathrm{NaCl}, 1$ mM EDTA, 1\% Triton X-100, 1\% sodium deoxycholate, 0.1\% SDS) containing 1X HaltTM Protease \& Phosphatase Inhibitor cocktail (Sigma-Aldrich). The lysate was incubated on ice for $30 \mathrm{~min}$ and centrifuged for $10 \mathrm{~min}$ in a refrigerated microfuge. Supernatants were assayed for total protein using the BCA Protein Quantitation kit (Pierce, Thermo Scientific). Protein $(15 \mu \mathrm{g})$ was separated on a $12 \%$ SDS-PAGE gel before transfer to an Immun-blot PVDF membrane (Roche Diagnostics). Membranes were incubated with anti-human $\alpha$-actin primary (1:5000 dilution; Millipore) and secondary (1:10,000 dilution; Sigma-aldrich) antibodies and developed using Lumi-light Western Blotting substrate (Roche Diagnostics).

\section{Necrosis/Apoptosis Assay by Flow Cytometry}

Infected THP-1 cells were collected, washed twice with PBS and stained with Annexin-V and Propidium iodide (PI) using the FITC Annexin V Apoptosis Detection Kit I (BD Pharmingen), according to manufacturer's instructions. Apoptosis/necrosis induction was then measured by Flow cytometry using a FACSverse flow cytometer (BDbiosciences).

\section{In vivo Experiments}

\section{Animal Model of Sepsis: Mean Lethal Dose} Determination $\left(\mathrm{LD}_{50}\right)$ and Immune-Response Assays

The bacterial virulence for mice was determined in 6- to 8week old female (mice BALB/c, Charles River, France) by i.p. injection with ten-fold serially diluted bacterial suspensions in PBS. Mortalities were recorded only if the inoculated bacterium was recovered in pure culture from kidney or liver of moribund animals. The $\mathrm{LD}_{50}$ was calculated as described (Reed and Muench, 1938).

To determine the immune response during sepsis, groups of 6-8-week-old female were i.p. injected with $1 \times 10^{6}$ $\mathrm{CFU} /$ mouse, and mice were anesthetized at 2 , 4 , or $6 \mathrm{~h}$ postinfection. Blood was collected by cardiac puncture and samples were stored in RNA later at $4^{\circ} \mathrm{C}$ until RNA extraction. PBSinjected mice were used as controls. After blood extraction, mice were sacrificed and the spleen and liver were obtained to microbiologically confirm bacterial invasion. To this end, spleens and livers were mechanically disaggregated in $1 \mathrm{~mL}$ of PBS. The homogenate was inoculated completely into LB-1 media and was incubated overnight at $37^{\circ} \mathrm{C}$ with shaking. In parallel, a loop of the homogenate was directly streaked onto TSA plates. After incubation, $0.1 \mathrm{~mL}$ of the LB-1 culture was spread onto TSA1 plates. All seeded TSA-1 plates were incubated at $37^{\circ} \mathrm{C}$ for $24 \mathrm{~h}$. Plates were examined to confirm purity of the culture and randomly selected colonies were purified and serologically identified by agglutination with previously obtained specific antiYJ016 or anti-R99 rabbit polyclonal antibodies.

Murine RNA Processing for Gene Expression Analysis Total RNA was isolated using the Mouse RiboPure ${ }^{\mathrm{TM}}$-Blood RNA Isolation Kit (Invitrogen, Thermo Fisher Scientific) and treated for $45 \mathrm{~min}$ at $37^{\circ} \mathrm{C}$ with Turbo DNase ${ }^{\mathrm{TM}}$ (Ambion ${ }^{\mathrm{R}}$, Life Technologies). The concentration and purity of each RNA was checked in a Nanodrop 2000 Spectrophotometer (Thermo Scientific). To check the absence of genomic DNA, real-time qPCR was performed on the RNA samples by using Power SYBR ${ }^{\circledR}$ green PCR Mastermix (Applied Biosystems ${ }^{\circledR}$, Life Technologies) and $B 2 m$ and Gusb primers. The Realtime $\mathrm{qPCR}$ was performed on a StepOnePlus ${ }^{\mathrm{TM}}$ Real-Time PCR System (Applied Biosystems), with the primers were taken from Primerbank. RNA from each mice group was then pooled after discarding samples that presented low quality/gDNA contamination. An RNA pool from a minimum of 3 animals was used to obtain the cDNA. The cDNA was transcribed from total RNA using All-in-One ${ }^{\mathrm{TM}}$ First-Strand cDNA Synthesis Kit $\left(\right.$ GeneCopoeia $\left.^{\mathrm{TM}}\right)$.

\section{Murine Gene Expression Analysis by qPCR Array}

To assess the global immune response activated by $V$. vulnificus during an in vivo infection, we designed a specific qPCR array for profiling the expression of 84 immune-related genes (Supplementary Table 2) (ExProfile Custom Gene qPCR Array, GeneCopoeia $\left.{ }^{\mathrm{TM}}\right)$. The PCR array included probes for genes involved in the general immune response against bacteria as well as genes involved in the specific immune response in eels against V. vulnificus (Callol et al., 2015b \& Unpublished 
results). The selected genes included: 12 genes for CCs, 18 genes for CKs, 8 genes related with the IFN response, 5 genes for transcription factors, 15 genes for pathogen recognition receptors (PRRs) and other cell receptors, 8 genes for signaling proteins, 5 genes related with the inflammasome response and 13 additional genes that included genes for complement proteins, apoptosis related genes, iron starvation, etc. (Supplementary Table 2). Real-time PCR was performed on cDNA using All-in-One ${ }^{\mathrm{TM}}$ qPCR Mix (GeneCopoeia ${ }^{\mathrm{TM}}$ ) and the customized Gene qPCR Array (GeneCopoeia ${ }^{\mathrm{TM}}$ ), on a StepOnePlus ${ }^{\mathrm{TM}}$ Real-Time PCR System. The threshold cycle (CT) values were determined to establish the relative RNA levels of the tested genes, and the fold-change in gene expression of $V$. vulnificus infected mice compared with uninfected control mice was calculated using the GeneCopoeia analysis tool for custom arrays. Six different housekeeping genes included in the array (Supplementary Table 2) were used in the analysis. Each treatment (strain and/or infection time) was performed twice, on separate days, and assessed in two different arrays independently, before being analyzed together as replicates with the GeneCopoeia analysis tool.

\section{Expression of $r t x A 1_{3}$ In vivo}

The expression of $r t x A_{3}$ and $v v h a$ genes was also determined in the blood samples from $V$. vulnificus $\mathrm{R} 99$ infected mice. The real-time qPCR was performed on the same cDNA samples used for the customized gene qPCR array. Real-time PCR was performed on cDNA using Power SYBR ${ }^{\circledR}$ green PCR Mastermix on a StepOnePlus ${ }^{\mathrm{TM}}$ Real-Time PCR System. The CT values were determined with StepOne Software v2.0 to establish the relative RNA levels of the tested genes, using recA gene as housekeeping gene. In Bt2-SerE infected mice, the value of expression of each gene in mice infected for $2 \mathrm{~h}$ was set equal to 1 , and then the fold increase in gene expression was calculated in mice infected for 4 and $6 \mathrm{~h}$. In Bt1-RtxA1 1 infected mice, the value of expression of $\mathrm{rtxA}_{1}$ in mice infected with the YJ016 $\Delta$ rtxA1 $1_{1}$ mice was set equal to 1 , and then the fold increase in gene expression was calculated in mice infected with the YJ016 strain. The bacterial primers used are listed in Supplementary Table 1.

\section{Analysis of Data}

We created Venn diagrams using the software available at http:// bioinformatics.psb.ugent.be/webtools/Venn/ (Bioinformatics and Evolutionary Genomics group at Ghent University). Heat maps were created using the free software MultiExperiment Viewer $(\mathrm{MeV})$, available at http://mev.tm4.org/. For PCA, we created a correlation matrix using Past v3.13 program (Hammer et al., 2001). Then a 3D graph was generated using the excel macro "Excel 3D Scatter Plot' v2.1", available at http://www. doka.ch/Excel3Dscatterplot.htm.

\section{Ex vivo Experiments Model for Hemochromatosis (hm)}

The ex vivo model for $\mathrm{hm}$ consisted of supplementing commercial human serum (Sigma-Aldrich, Spain) with $\mathrm{FeCl}_{3}$ at a final concentration of $10 \mu \mathrm{M}$ (iron content within the range of those typical of hemochromatosis) (Bacon et al., 2011) (hmserum). Then, hm-blood was prepared by resuspending human blood cells in hm-serum. To this end, whole human blood was obtained from volunteers recruited from the University of Valencia. Blood was collected by venipuncture using lithium heparin tubes (BD Vacutainer ${ }^{\circledR}$, BD Biosciences). Blood cells were separated by centrifugation, erythrocytes were lysed with ACK buffer $\left(0.15 \mathrm{M} \mathrm{NH}_{4} \mathrm{Cl}, 10 \mathrm{mM} \mathrm{KHCO}_{3}, 1 \mathrm{mM}\right.$ EDTA), and the number of blood cells was determined by microscopic counting. Finally, $2.5 \times 10^{6}$ blood cells were resuspended in $150 \mu \mathrm{l} \mathrm{of} \mathrm{hm-serum.} \mathrm{Hm-blood} \mathrm{and} \mathrm{hm-serum} \mathrm{were} \mathrm{immediately}$ used.

\section{$\mathrm{Hm}$-Serum Resistance and $r t x A 1_{3}$ and $v v h a$ Expression in hm-Blood}

Growth in normal and hm-serum was performed by inoculating R99 or YJ016 cells at a MOI (multiplicity of infection; bacteria: human cell) of 2 , and taking samples for bacterial counts on TSA- 1 plates at $0,2,4$, and 6 h. $r t x A 1_{1}$ and $r t x A 1_{3}$ expression was followed in normal and hm-blood by taking samples at the same time intervals. Cells were pelleted and the RNA was isolated. Different RNA isolation kits were tested beforehand, and the GenElute ${ }^{\mathrm{TM}}$ Mammalian Total RNA Miniprep Kit (SigmaAldrich) was found to produce higher yields and better RNA purity. RNA was treated with Turbo DNase ${ }^{\mathrm{TM}}$, and cDNA was transcribed from total RNA using random hexonucleotide primers (Takara Bio Europe), and Maxima ${ }^{\mathrm{TM}} \mathrm{H}$ Minus Reverse Transcriptase (Thermo Scientific). Real-time PCR was performed and analyzed as described above, and the bacterial primers used are listed in Supplementary Table 1.

\section{Ethics Statement}

Whole human blood was obtained from healthy volunteers recruited among the staff of the Microbiology \& Ecology Department from the University of Valencia. Donors gave their written informed consent to participate in the study, in accordance with the Declaration of Helsinki. They completed a health questionnaire, and doctor's consent for their inclusion in the study was obtained. Only healthy donors were considered; volunteers with anti-inflammatory or immunosuppressive prescribed medication, diabetes mellitus, chronic inflammatory disease, or symptoms of recent infection were excluded. Volunteers were recruited specifically for the purpose of this experiment, and blood was collected at the Burjassot campus medical service of the University of Valencia. Assays were approved by the Institutional Committee on Human Research (project license H1487946643442).

All assays involving mice were approved by the Institutional Animal Care and Use Committee and the local authority (Conselleria de Agricultura, Medio Ambiente, Cambio Climático y Desarrollo Rural. Generalitat Valenciana), following European Directive 2010/63/EU and the Spanish law "Real Decreto" $53 / 2013$. Murine infections were performed under the project licenses 2014/VSC/PEA/00195 and 2016/VSC/PEA/00069, and were carried out in the Research Animals core facility of the University of Valencia. 
The experiments performed in this study are part of the working plan that was approved and supported by the Ministry of Economy Industry and Innovation (MINECO) of Spain: Grant AGL 2014-58933-P.

\section{RESULTS}

\section{RtxA1 3 but Not VvhA Is Involved in Virulence for Mice}

The $\mathrm{LD}_{50}$ of R99 (Bt2-SerE) and YJ016 (Bt1-RtxA1 1 ) strains was identical $\left(1 \times 10^{6} \mathrm{CFU} /\right.$ mouse or $\left.5 \times 10^{4} \mathrm{CFU} / \mathrm{gr}\right)$. The deletion of $v v h A$ in $\mathrm{R} 99$ strain did not change $\mathrm{LD}_{50}$ value, while the deletion of both copies of $r t x A 1_{3}$, or both copies plus $v v h A$, caused an increase in more than 2 logarithmic units of the $\mathrm{LD}_{50}\left(>10^{8} \mathrm{CFU} /\right.$ mouse). Previously, our group had shown that the double revertant strain (with both copies of $r t x \mathrm{Al}_{3}$ reintroduced) had the same virulence level in $\mathrm{C} 3 \mathrm{H} / \mathrm{HeN}$ mice as the wild-type strain, confirming that the reduction in virulence of the $\mathrm{RtxAl}_{3}$ mutant was not caused by an unexpected mutation that had occurred elsewhere (Lee et al., 2013). These results suggest that $\mathrm{RtxA}_{3}$ but not VvhA is involved in mouse death caused by Bt2-SerE strains.

\section{RtxA1 ${ }_{3}$ Is a Toxin with Actin-Cross-Linking Activity, Responsible for Early Death of Human Endotheliocytes and Monocytes In vitro}

$\mathrm{RtxAl}_{3}$ from Bt2-SerE has been reported to be involved in early cell death (Lee et al., 2013). To eliminate the possibility that VvhA could interfere with $\mathrm{RtxAl}_{3}$ in Bt2-SerE, we infected human vascular endotheliocytes (ECV304 cell line) and monocytes (THP-1 cell line) with R99 strain and its derivative mutants (R99 $\left.\Delta \Delta r t x A 1_{3}, \mathrm{R} 99 \Delta v v h A, \mathrm{R} 99 \Delta \Delta r t x A 1_{3} \Delta v v h A\right)$ and incubated the infected cells for $6 \mathrm{~h}$. The R99 strain started to lyse cells before $4 \mathrm{~h}$ post-infection (hpi) with a maximum at $5 \mathrm{~h}$ that was maintained up to $6 \mathrm{hpi}$, without significant differences with R99 $\Delta v v h A$ strain at any sampling point. In contrast, there were significant differences in cell lysis between $\mathrm{R} 99$ and $\mathrm{R} 99 \Delta \Delta r t x A 1_{3}$ strains at 4 and $5 \mathrm{hpi}$, and between R99 and $\mathrm{R} 99 \Delta \Delta r t x A 1_{3} \Delta v v h A$ strains at 4, 5, and 6 hpi (Figure 2A). Similar results were obtained by infecting human monocytes (data not shown). Taken together, our results suggest that both toxins do not overlap at short term (before $6 \mathrm{hpi}$ ), with RtxA1 $1_{3}$ the main factor responsible for early cell lysis caused by Bt2-SerE in vitro. Finally, a light lytic effect was also found at $6 \mathrm{hpi}$ when the mutant in both toxins was tested, indicating that other toxins apart from $\mathrm{RtxA}_{3}$ and VvhA could also produce cell death in vitro.

To find out if $\mathrm{RtxAl}_{3}$ could cause cell death by apoptosis, we analyzed it by flow cytometry (Figure 2B and data not shown). After $3.5 \mathrm{~h}$ of in vitro infection of human monocytes, the percentage of cells in late apoptosis (stained with both annexin $\mathrm{V}$ and PI) was close to $100 \%$ in the wild-type strain, whereas only $27 \%$ of the cells were in this stage after being infected with the $\operatorname{rtxAl}_{3}$ mutant (Figure 2B). No evidence of cell death by apoptosis was observed in endothelial cells (data not shown).
This result suggests that $\mathrm{RtxAl}_{3}$ can induce early apoptosis in human monocytes but not in endotheliocytes cultured in vitro.

$\mathrm{RtxA}_{3}$ contains an ACD domain that is predicted to have actin cross-linking activity due to its high similarity with the ACD domain of MARTX of $V$. cholerae (Sheahan et al., 2004; Kwak et al., 2011; Roig et al., 2011). Thus, we next sought to determine if the ACD domain and, in consequence, RtxA1 $1_{3}$, could also have this activity by infecting human monocytes and endotheliocytes with R99, R99 $\Delta \triangle r t x A_{3}$, and $\mathrm{R} 99 \Delta \triangle A C D$ strains and detecting actin cross-linking by western blotting (Figure 3). As early as 1 hpi, R99 strain induced the formation of actin oligomers that was dependent on the infection dose, and progressed with the infection time (Figure 3 ). Thus, at $3 \mathrm{hpi}$, any native actin ( $42 \mathrm{Kda}$ ) was left in the samples had all been converted to an oligomer of $\sim 250 \mathrm{KDa}$ (Figure 3). As expected neither R99 $\Delta \Delta r t x A 1_{3}$ nor $\mathrm{R} 99 \triangle \triangle A C D$ strains induced actin polymerization, at any sampling point. All these results proved that ACD domain of $V$. vulnificus and, in consequence, RtxA1 ${ }_{3}$, has actin-cross linking activity.

We also tested if this domain was essential to induce apoptosis in human monocytes (Figure 2B). The mutant in the ACD domain produced the same degree of apoptosis as the wildtype strain, which suggests that this domain is not involved in apoptosis of human monocytes in vitro.

\section{V. vulnificus Bt2-SerE R99, but Not Bt1-RtxA1 1 YJ016, Induces an Early and Strong Immune Response in Mice}

In order to test if $V$. vulnificus Bt2-SerE induces an early and strong immune response in mice that could be compatible with a CK storm (CKS), we analyzed the transcription of 84 murine genes in blood from infected and non-infected mice by using a sepsis model of infection. We also inoculated mice with YJ016 for comparative purposes.

Prior to the expression analysis, we checked that the inoculated strain had colonized the infected animals internally by isolating it from spleen, liver, and blood. Both strains were recovered in pure culture from all the internal organs of the infected mice but only after enrichment, which prevented us from calculating an organ colonization index. No bacteria were recovered from internal organs of non-infected mice.

Then, we determined murine DEGs (differentially expressed genes) in response to each of the strains by comparing data between infected and non-infected mice. Results are summarized in Figures 4, 5.

The immune response against R99 strain was very fast and strong, and remained over time: it included 56 out of the 84 selected genes (67\%), all of them up-regulated (Table 2), from which 21 (out of 56 or $37.5 \%$ ) were already up-regulated at 2 hpi, and 16 of them (out of 21 , or $76.2 \%$ ) continued to be upregulated at $6 \mathrm{~h}$ (Figure 4). The core DEGs (genes up-regulated at all time points) contained genes for: (i) two interleukins with a strong pro-inflammatory and immune-regulatory activity (Illa, Il1b) plus their receptor (Il1r2) and its agonist (Il1rn); (ii) four CKs and chemokines (CCs) (Ccl4, Il3, Il4, and Ill7a); (iii) one type I interferon (IFN) (Ifnb1); (iii) Nfkbl, a subunit of the 

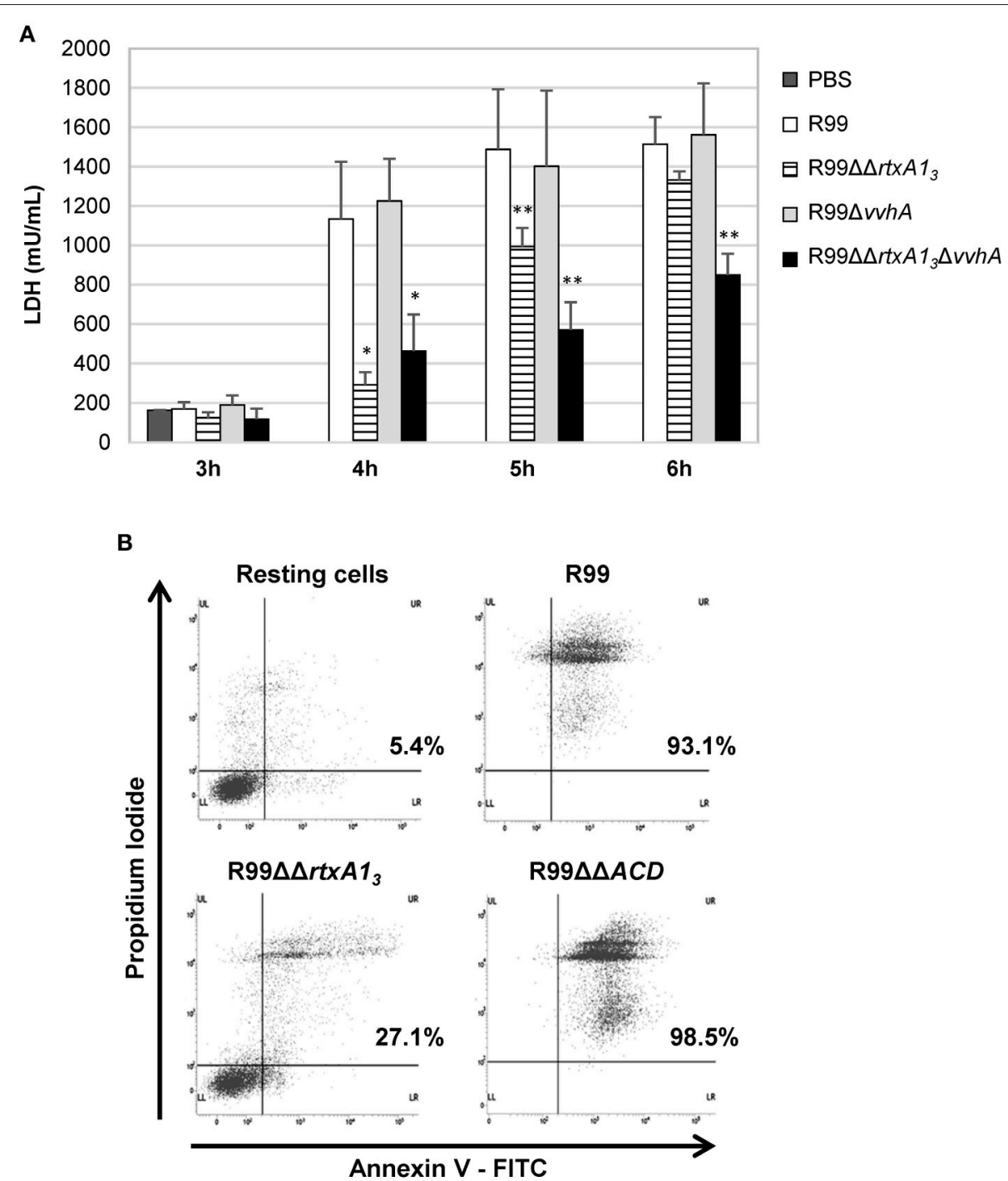

FIGURE 2 | V. vulnificus itxA13 gene is involved in cell damage induction and apoptosis in human monocytes. (A) Live cells of $V$. vulnificus R99, R99 $\Delta \Delta r$ txA13 mutant, R99 $\Delta v v$ ha mutant, and the double R99 $\Delta \Delta r$ txA $1_{3} \Delta v v h A$ mutant, were added at a MOI of 2 to ECV304 cells. Cells were incubated with the bacteria for the appropriate time intervals and then cell culture supernatants were collected and assessed for lactate dehydrogenase (LDH) levels. Data represent mean values \pm standard deviation from three independent experiments. The significance of the differences was determined using the Student's two-tailed $t$-test; ${ }^{\star} p<0.05$ and ${ }^{\star \star} p<$ 0.01 compared with R99 infected cells. (B) THP-1 cells were infected for $3.5 \mathrm{~h}$ with V. vulnificus R99, R99 $\Delta \Delta r$ txA13, and R99 $\Delta \Delta A C D$ strains, at a MOI of 10 . The induction of apoptosis/necrosis was then measured by Flow Cytometry using the FITC Annexin V Apoptosis Detection Kit I. Results show histograms from one representative experiment of two.

transcription factor complex NF-кB; (iv) Tlr9, an intracellular PRR that recognizes CpG motifs of microbial DNA; (v) Dusp1 (MKP-1), the dual specificity protein phosphatase 1, a key phosphatase involved in a negative feedback loop regulating the MAPK pathway; (vi) Ank1, a protein with roles in cell motility, proliferation or cell contact; (vii) $C 4 b$, the complement component 4; (viii) Kras, a GTPase; and, ix) Nos2, the inducible nitric oxide synthase.

Among the DEGs that were up-regulated exclusively at $4 \mathrm{~h}$ were genes for: (i) another type I IFN (Ifna2) and its receptor (Ifnar 1), the receptor for IFN- $\gamma$ (Ifngr 1) and an IFN regulatory factor (Irf1); (ii) one CC involved in the recruitment and activation of granulocytes $(\mathrm{Cxcl3})$ and two pro-inflammatory CKs (Il7, Lta); (iii) three proteins of the inflammasome complex (Nlrc4, Pycard, and Casp1); (iv) two transcription factors (Jun and Rela); (v) four PRR and receptors (Tlr2, Cd14, Nod2, Cd82) and (iv) other genes such as, Tfrc, the transferrin receptor (Figure 4).

Finally, at 6 hpi there were still 32 genes up-regulated (out of 56 , or $57 \%$ ), 8 of them exclusively at this time. These included the genes for: (i) the CCs CCL3 (MIP-1 $\alpha$ ) and CCL5 (RANTES), involved in the recruitment and activation of different immune cells; (ii) the CXC CCs, CXCL1, and CXCL2, which are chemoattractant for neutrophils, granulocytes and hematopoietic stem 


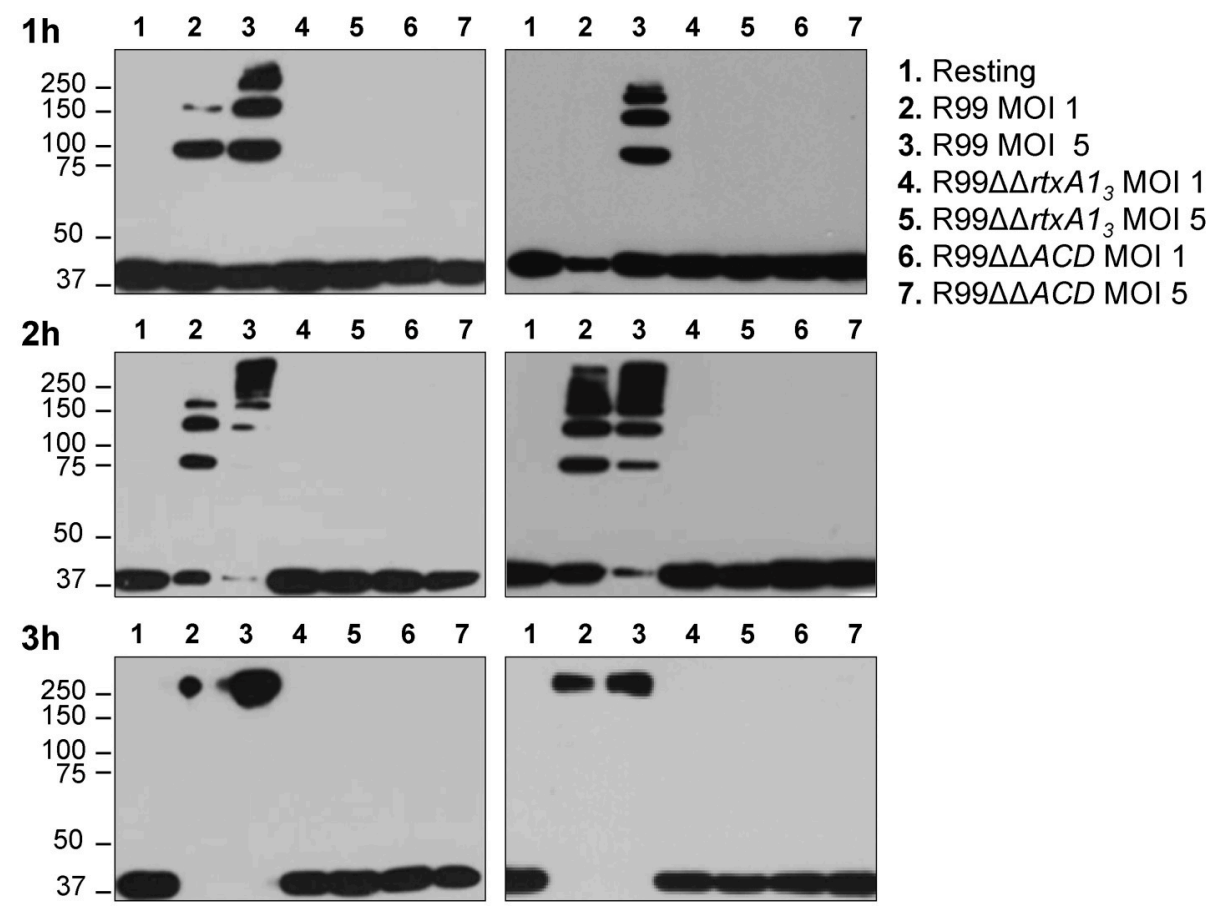

FIGURE 3 | Role of the ACD domain in actin polymerization. V. vulnificus R99, R99 $\Delta$ rtxA13, and R99 $\Delta A C D$ cells were added at MOls of 1 and 5 to THP-1 suspension cells and ECV304 adherent cells for 1, 2, and $3 \mathrm{~h}$. Cell lysates were separated by SDS-PAGE and western blotted to detect polymerization of $\alpha$-actin. Data are representative of two independent experiments.

cell, respectively; (iii) the C-type lectin CLEC4D; and (iv) LCN2, a protein that limits bacterial growth by sequestrating iron.

The maximum number of up-regulated genes was reached at $4 \mathrm{hpi}$, at which time a total of 47 genes were activated (Figure 4). For that reason, we selected this time point for the immune response analysis against the selected Bt1- RtxA $1_{1}$ strain.

Strain YJ016 induced a completely different immune response that involved a higher number of DEGs (76 vs. 47) most of them down-regulated (Figure 5). Thus, only 29 out of 76 genes were up-regulated, 14 in common with strain R99 (Figure 5B). Again, the genes for IL- $1 \alpha$, IL-1 $\beta$, and the IL- 1 receptor, belonging to the IL-1 family, were up-regulated, stressing its importance as an immune-mediator system against any $V$. vulnificus strain. Also, the genes for the CK IL-6 and for the CCs CXCL3 and PF4 (or CCXL4) were up-regulated. PF4 showed the highest value of fold-change, 232, a value that was significantly higher than the one induced by strain R99 (2- and 22-fold-change at 4 and 6 h, respectively) (Table 2). PF4, a CXC CC produced by activated platelets during its aggregation, has a large number of biological effects such as, activation of different immune cells (NK cells, T cells, monocytes, and granulocytes), differentiation and chemotaxis, inhibition of endothelial cell migration, a dual pro- and anti-coagulant effect mediated by platelet-aggregation potentiation (Sandset, 2012) and Protein C activation (Slungaard and Key, 1994), respectively. Other genes induced by both strains were the IFN regulatory factors Irf1 and Irf2, the lipopolysaccharide receptors Tlr4 and Cd14, and Dusp1.
Among the genes uniquely induced by YJ016 strain were $\mathrm{Ccl} 2$ and Tnfo (Figure 5B). Remarkably, the pattern of induction of PRRs was very different between both strains; YJ016 induced strongly the expression of the C-type lectin genes Clec4d and Clec4e, and Syndecan-4 (Snd4) whereas R99 induced Tlr2 and genes for intracellular receptors such as, NOD2 (located in the cytoplasm and recognizing muramyl dipeptide from grampositive and negative bacteria; Kawai and Akira, 2009) and TLR9. Indeed, the genes for these two intracellular receptors were down-regulated by YJ016 strain (Figure 5C). There were also other genes up-regulated by YJ016 strain at 4 hpi that were not induced by the R99 strain at this time point, but that were induced by the R99 strain at 2 or $6 \mathrm{hpi}$, such as, Ccl3, Ccl5, Ccl6, Cxcl1, Cxcl2, Mapk6, Mapk8, and Lcn2, which was strongly up-regulated by both strains (Figures 4, 5, and Table 2).

Taking a closer look at the genes down-regulated by strain YJ016 (Figure 5C), we found genes that were up-regulated by the R99 strain, such as, the transcription factors genes Fos, Jun, Nfkbl, and RelA, a number of CCs and CKs genes (Illrn, Il3, Il4, IL7, IL17a, Csf2, Lta), IFN related genes (Ifna2, Ifnb1, Ifnar1, and Ifngr1), and the genes that encode proteins for the inflammasome complex (Nlrc4, Aim2 and Casp1).

Comparing the global results, it can be concluded that R99 but not strain YJ016 induces an early and strong inflammatory response that could be compatible with a CKS. 


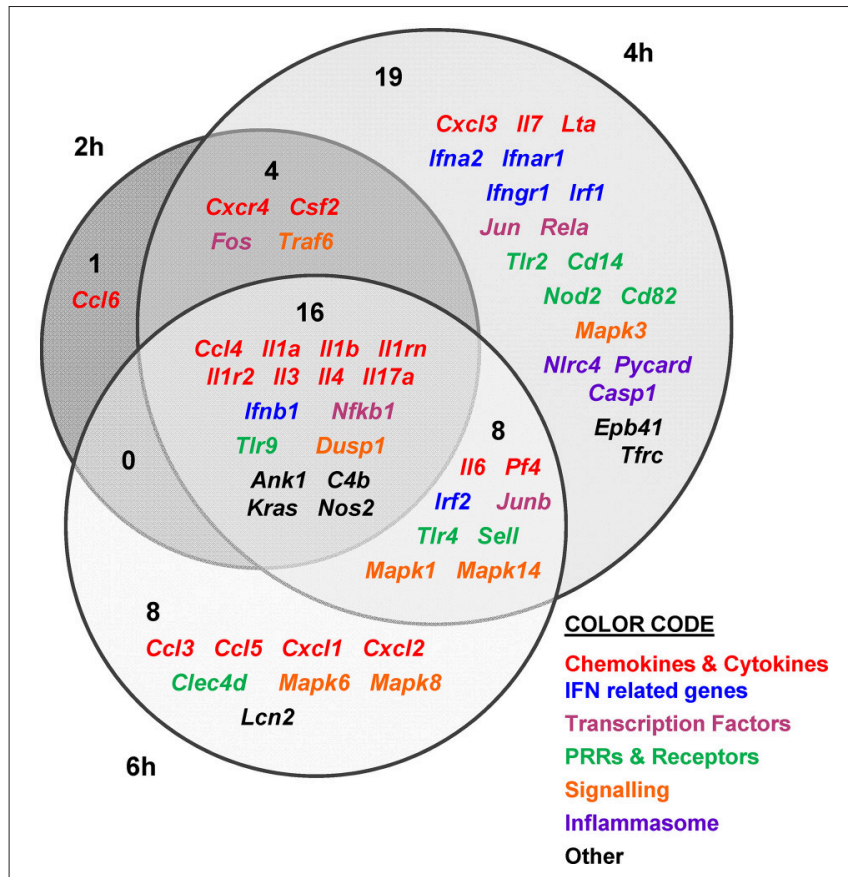

FIGURE 4 | V. vulnificus Bt2-SerE R99 strain induces the early up-regulation of a large number of immune-related genes. Venn diagram depicting the overlap of the 56 immune-related genes that are differently up-regulated between R99 strain infected-mice for 2, 4, or 6 h, when compared with uninfected mice. Only genes up-regulated more than 1.3 were considered.

\section{RtxA1 3 , but Not RtxA1 1 , Induces a Strong Early Immune Response against V. vulnificus in Mice}

We hypothesized that $\mathrm{RtxA}_{3}$ is a key virulence factor in sepsis. To examine this, we compared the immune response of mice against strain R99 and its derivative mutant R99 $\Delta \Delta r x A 1_{3}$ at 4 hpi. In parallel, we also compared the immune response of mice against strains YJ016 and YJ016 $\Delta r t x A 1_{1}$.

Prior to RNA analysis, we checked again the colonization process of internal organs by isolating the inoculated strain from spleen and liver of infected mice. Again, we recovered pure cultures of all the strains, including both mutants, from all the organs and sampling times, but only after enrichment.

In parallel, we checked that $r t x A 1_{3}$ and $r t x A 1_{1}$ were being expressed in vivo at $4 \mathrm{hpi}$, a time at which blood was sampled for transcription analysis. As expected, both bacterial genes were transcribed in vivo although with different fold-change values (average fold-change of $2.5\left[r t x A 1_{3}\right]$ vs. $\left.4.8\left[r t x A 1_{1}\right]\right)$. In addition, we followed the time course of $r x \mathrm{Al}_{3}$ and $v v h A$ transcription to discard the possibility that both toxins could act together in vivo at the selected sampling time. $r t x \mathrm{Al}_{3}$ was detected at $2 \mathrm{hpi}$, being up-regulated at 4 (average fold-change of 2.5) and 6 (average foldchange of 3.0) hpi, while $v v h A$ was only induced at 6 hpi although with a higher fold-change (average fold-change 4.0). These results prove that of the two toxins, only $r t x \mathrm{Al}_{3}$ is relevant at $4 \mathrm{hpi}$.
We then compared the immune response generated by each of the wild-type strains with that induced by its mutant (Figure 6). The R99 strain specifically induced the expression of a large number of genes (32) including those for CKs (Il3, Il4, Il6, $I l 7, I l 17 a, C s f 2$, and Lta), for IFN-related proteins (Ifna2, Ifnb1, Ifnar1, and Ifngr1), for inflammasome components (Nlrc4 and Casp1) and for a large number of transcription factors (Fos, $J u n, J u n b, N f k b 1$, and Rela) (Figure 6A). In contrast, there were significantly fewer differences between the responses generated by the wild-type YJ016 strain and its mutant (Figure 6B); only 13 genes were induced by the wild-type strain and not by the mutant, and the great majority of them (9/13) were also induced by the R99 strain, the R99 $\Delta r t x A 1_{3}$ mutant, or both (Ccl3, Cxcl1, Cxcl2, Cxcl3, Il1a, Il6, Cd14, Tlr4, and C3). The strong pro-inflammatory response induced by the R99 strain and not by its mutant would suggest that the activation of the CKS was mainly due to the $\mathrm{RtxAl}_{3}$ toxin.

We then globally compared the results of the qPCR array from the 4 groups of inoculated animals by performing a Heat Map (Figure 7). The pattern of gene expression induced by both $\mathrm{YJ} 016 \Delta r t x A 1_{1}$ and $\mathrm{R} 99 \Delta \Delta r t x A 1_{3}$ strains was very similar, with a significant number of genes down-regulated (Figure 7). Further, the pattern of gene expression induced by both $r t x A 1$ mutants was more similar to the one induced by YJ016 strain than to the one induced by strain R99 (Figure 7).

Only 7 out of the 84 selected genes were up-regulated by all four strains; (i) Illb and Il1r2; (ii) the genes for the IFN regulatory factors IRF1 and IRF2; (iii) Dusp1 and Mapk1; (iv) Sell, encoding L-selectin, a cell surface adhesion molecule required for binding and subsequent rolling of leucocytes on endothelial cells, facilitating their entry into secondary lymphoid tissues and inflammation sites; (v) Tfrc, encoding the transferrin receptor; and (v) PF4. This latter gene was by far the one most upregulated, reaching a 433 -fold increase (Table 2 ).

To comprehensively analyse the results, we performed a Principal Component Analysis (PCA) using the data from the mice infected with the wild-type strains and their correspondent mutants, all examined at $4 \mathrm{hpi}$. As shown in Figure 8A, the analysis confirmed that the immune responses against YJ016 and R99 were clearly different and that the responses against both rtxA1 mutants were very similar, regardless of the strain that harbored the mutation. Further, the response against R99 $\Delta \Delta r t x \mathrm{Al}_{3}$ was more similar to the one against YJ016 strain than to the one against its own parental strain (Figure 8A), which suggests that the strong immune response against strain R99 was mainly due to RtxA1 3 .

Finally, we repeated the PCA, including the data from the mice infected with strain R99 and analyzed at 2 and 6 hpi (Figure 8B). The analysis grouped immune response data into three clusters; the first corresponding to mice infected with the two rtxA1 mutants and YJ016 strain, all being analyzed at $4 \mathrm{hpi}$; the second group corresponded to mice infected with strain R99 and analyzed at 2 and $4 \mathrm{hpi}$; and the third group corresponded to mice infected with strain R99 and analyzed at 6 hpi. Curiously, this last group was closer to the first one (Figure 8B). This last result, together with the previous ones obtained by PCA, strongly 


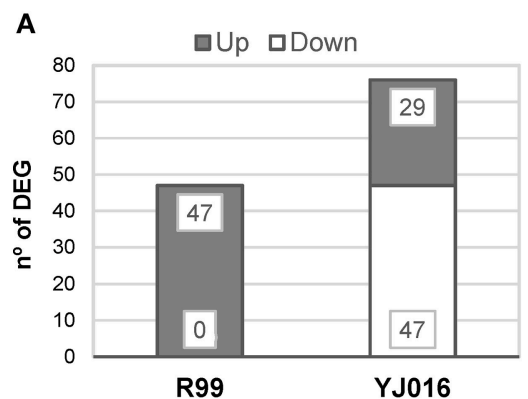

\section{C}

Down-regulated genes in YJ016 infected-mice
Chemokines \& Cytokines
Ccl12 Ccl20 II1m II3 II4 II7 $\| 12 a ~ I 12 b$
II17a II18 Csf2 Csf3 Lta Vegfa $\| 10$
IFN related genes
Ifna2 Ifnb1 Ifnar1 Ifng Ifngr1
Transcription Factors
Fos Jun Nfkb1 Rela
PRRs \& Receptors
Ly96 TIr5 TIr9 Nod1 Nod2 Clec1a Cd82
Signalling
Mapk3 Mapk14 Traf3 Traf6
Inflammasome
NIrc4 Aim2 Casp1
Other
Ank1 Epb41 Hc Casp3 Bax Kras
Trp53 Nos2 Thbd

B

$\underline{\text { Up-regulated genes in R99 and YJ016 infected-mice }}$

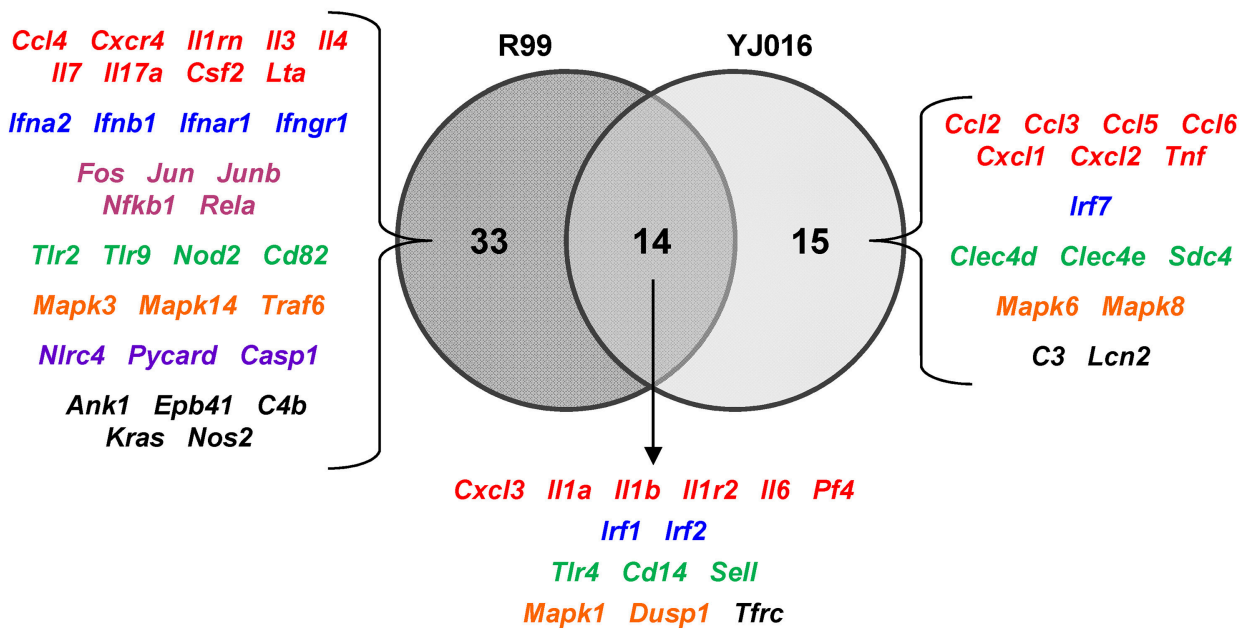

FIGURE 5 | Bt1-RtXA1 1 and Bt2-SerE elicit a different immune response. (A) Number of genes up- and down-regulated in mice infected with the Bt2-SerE R99 strain and the Bt1-RtXA1 Y YJ016 strain. (B) Venn diagram depicting the overlap of the up-regulated genes in response to R99 and YJ016 strain when compared with uninfected mice. (C) List of genes down-regulated after the infection with the Bt1-RtXA1 Y YJ016 strain. In all cases, only genes up-regulated more than 1.3 or down-regulated more than 0.5 were considered.

suggests that the immune response due to $\operatorname{RtxA} 1_{3}$ had a peak at $4 \mathrm{~h}$ and decreased at $6 \mathrm{hpi}$.

\section{$r t x A 1_{1}$ and $r t x A 1_{3}$ Are Expressed in the Presence of Human Blood Cells as Determine by an Ex vivo Model of} Hemochromatosis

We used an ex vivo model that simulates sepsis in hemochromatosis (hm) human patients and followed the transcription of $r t x A 1$ genes after the co-culture of the bacteria with human PBMCs (peripheral blood mononuclear cells).

Real time qPCR results showed that the expression of the rtxA1 gene was up-regulated in both YJ016 and R99 strains after being in contact with human cells for 2 h. At 4 and 6 hpi, the genes showed similar expression levels as seen at time 0 (Figure 9A). There was a noticeable difference between the expression of $r t x A 1_{1}$ and $r t x A 1_{3} ; r t x A 1_{3}$ was up-regulated 12fold when compared with time 0 , whereas the $r t x A 1_{1}$ presented a smaller up-regulation (around 3.5-fold). 
TABLE 2 | Fold change value of genes when compared with uninfected mice.

\begin{tabular}{|c|c|c|c|c|c|c|}
\hline & \multicolumn{3}{|c|}{ R99 } & \multirow[t]{2}{*}{ YJ016 (4 h) } & \multirow[t]{2}{*}{ R99 $\Delta r t x A 1_{3}(4 \mathrm{~h})$} & \multirow[t]{2}{*}{ YJ016 $\Delta r t x A 1,(4 \mathrm{~h})$} \\
\hline & $2 \mathrm{~h}$ & $4 \mathrm{~h}$ & $6 \mathrm{~h}$ & & & \\
\hline \multicolumn{7}{|c|}{ CHEMOKINES } \\
\hline Ccl2 & 0.900 & 0.990 & 0.712 & 2.613 & 0.616 & 0.130 \\
\hline $\mathrm{Cc} / 3$ & 0.900 & 0.990 & 1.425 & 21.010 & 1.748 & 0.368 \\
\hline Cc/4 & 10.157 & 3.940 & 7.799 & 1.249 & 1.181 & 0.497 \\
\hline Ccl5 & 0.601 & 0.986 & 3.827 & 4.945 & 9.320 & 3.907 \\
\hline Cc/6 & 5.078 & 0.702 & 0.972 & 2.512 & 1.666 & 1.403 \\
\hline CCl12 & 0.900 & 0.990 & 0.688 & 0.115 & 0.148 & 0.062 \\
\hline Ccl2O & 0.900 & 1.008 & 0.688 & 0.041 & 0.151 & 0.062 \\
\hline$C x \mathrm{C} / 1$ & 0.882 & 0.992 & 2.818 & 41.006 & 3.425 & 0.509 \\
\hline Cxcl2 & 0.943 & 1.041 & 2.864 & 41.896 & 3.479 & 0.518 \\
\hline $\mathrm{CxCl3}$ & 0.884 & 1.404 & 0.676 & 41.053 & 2.404 & 0.507 \\
\hline Pf4 & 0.882 & 2.038 & 22.307 & 231.676 & 433.480 & 367.456 \\
\hline Cxcr4 & 5.074 & 2.798 & 0.960 & 1.252 & 1.665 & 0.991 \\
\hline \multicolumn{7}{|c|}{ CYTOKINES } \\
\hline $111 a$ & 3.612 & 2.802 & 2.791 & 20.162 & 3.362 & 0.354 \\
\hline $111 b$ & 1.804 & 1.983 & 2.765 & 20.033 & 26.816 & 7.953 \\
\hline $1 / 1 r n$ & 1.817 & 1.993 & 1.394 & 0.080 & 0.301 & 0.125 \\
\hline $1 / 1 r 2$ & 1.840 & 2.035 & 1.438 & 7.244 & 6.848 & 2.870 \\
\hline //3 & 2.540 & 1.985 & 1.952 & 0.056 & 0.295 & 0.178 \\
\hline 114 & 3.620 & 1.988 & 1.371 & 0.039 & 0.297 & 0.088 \\
\hline 116 & 1.282 & 1.992 & 7.729 & 2.514 & 0.420 & 0.125 \\
\hline 117 & 1.276 & 1.394 & 0.982 & 0.056 & 0.297 & 0.176 \\
\hline $1 / 12 a$ & 0.900 & 0.990 & 0.688 & 0.057 & 0.148 & 0.180 \\
\hline $1 / 12 b$ & 0.900 & 0.990 & 0.688 & 0.057 & 0.148 & 0.064 \\
\hline $1117 a$ & 3.602 & 4.000 & 1.397 & 0.111 & 0.149 & 0.177 \\
\hline 1118 & 0.900 & 1.010 & 0.688 & 0.163 & 0.308 & 0.259 \\
\hline Csf2 & 1.841 & 1.437 & 0.705 & 0.160 & 0.303 & 0.128 \\
\hline Csf3 & 0.900 & 1.013 & 0.688 & 0.325 & 0.151 & 0.064 \\
\hline Tnf & 0.939 & 1.011 & 0.721 & 2.610 & 1.232 & 0.520 \\
\hline Lta & 0.900 & 1.426 & 0.688 & 0.058 & 0.152 & 0.090 \\
\hline Vegfa & 0.636 & 0.700 & 0.061 & 0.020 & 0.075 & 0.044 \\
\hline 1110 & 0.446 & 0.989 & 0.687 & 0.039 & 0.209 & 0.124 \\
\hline \multicolumn{7}{|c|}{ IFN RELATED GENES } \\
\hline Ifna2 & 0.939 & 1.441 & 0.688 & 0.039 & 0.221 & 0.090 \\
\hline Ifnb1 & 1.822 & 1.396 & 2.788 & 0.040 & 0.429 & 0.127 \\
\hline Ifnar1 & 0.637 & 1.392 & 0.976 & 0.111 & 0.417 & 0.176 \\
\hline Ifng & 0.900 & 0.990 & 0.688 & 0.116 & 0.151 & 0.063 \\
\hline Ifngr1 & 1.281 & 1.975 & 0.487 & 0.445 & 0.595 & 0.354 \\
\hline Inf1 & 0.919 & 1.410 & 0.675 & 5.167 & 2.426 & 1.443 \\
\hline Inf2 & 0.916 & 1.397 & 1.395 & 2.559 & 3.403 & 2.026 \\
\hline IIf7 & 0.900 & 0.990 & 0.688 & 1.864 & 1.241 & 0.520 \\
\hline \multicolumn{7}{|c|}{ TRANSCRIPTION FACTORS } \\
\hline Fos & 2.573 & 1.984 & 0.994 & 0.079 & 0.298 & 0.125 \\
\hline Jun & 0.899 & 1.985 & 0.689 & 0.111 & 0.147 & 0.124 \\
\hline Junb & 0.893 & 1.403 & 2.769 & 0.630 & 0.833 & 0.351 \\
\hline Nfkb1 & 7.268 & 3.969 & 1.377 & 0.080 & 0.424 & 0.177 \\
\hline Rela & 0.448 & 1.397 & 0.682 & 0.111 & 0.295 & 0.175 \\
\hline \multicolumn{7}{|c|}{ PRRS AND RECEPTORS } \\
\hline TIr2 & 0.428 & 1.982 & 0.685 & 0.626 & 0.416 & 0.248 \\
\hline
\end{tabular}


TABLE 2 | Continued

\begin{tabular}{|c|c|c|c|c|c|c|}
\hline & \multicolumn{3}{|c|}{ R99 } & \multirow[t]{2}{*}{ YJ016 (4 h) } & \multirow[t]{2}{*}{$\mathrm{R} 99 \Delta r t x A 1_{3}(4 \mathrm{~h})$} & \multirow[t]{2}{*}{ YJ016 $\Delta r t x A 1_{1}(4 \mathrm{~h})$} \\
\hline & $2 \mathrm{~h}$ & $4 \mathrm{~h}$ & $6 \mathrm{~h}$ & & & \\
\hline TIr4 & 0.944 & 2.083 & 1.435 & 1.314 & 1.748 & 0.735 \\
\hline Cd14 & 0.900 & 1.443 & 0.688 & 5.219 & 1.737 & 0.365 \\
\hline Ly96 & 0.900 & 0.987 & 0.171 & 0.028 & 0.104 & 0.031 \\
\hline TIr5 & 0.900 & 1.008 & 0.688 & 0.041 & 0.215 & 0.064 \\
\hline Tlr9 & 3.628 & 1.989 & 1.369 & 0.111 & 0.596 & 0.249 \\
\hline TIr13 & 0.900 & 0.990 & 0.688 & 0.926 & 2.464 & 1.036 \\
\hline Nod1 & 0.900 & 0.990 & 0.688 & 0.164 & 0.153 & 0.184 \\
\hline Nod2 & 0.945 & 2.079 & 0.729 & 0.234 & 0.310 & 0.090 \\
\hline Clec1a & 0.900 & 1.008 & 0.688 & 0.039 & 0.148 & 0.063 \\
\hline Clec4d & 0.937 & 1.009 & 1.434 & 14.828 & 27.825 & 11.677 \\
\hline Clec4e & 0.900 & 1.015 & 0.710 & 10.415 & 13.945 & 4.134 \\
\hline Sdc4 & 0.652 & 0.990 & 0.496 & 5.073 & 0.852 & 0.506 \\
\hline Sell & 0.939 & 1.463 & 1.426 & 5.213 & 6.944 & 4.130 \\
\hline Cd82 & 0.893 & 1.393 & 0.688 & 0.224 & 0.297 & 0.177 \\
\hline \multicolumn{7}{|c|}{ SIGNALING } \\
\hline Mapk1 & 0.901 & 1.987 & 11.020 & 3.553 & 6.653 & 3.968 \\
\hline Mapk3 & 1.277 & 1.393 & 0.974 & 0.441 & 1.179 & 0.495 \\
\hline Mapk6 & 0.900 & 0.990 & 1.431 & 1.851 & 3.484 & 2.069 \\
\hline Mapk8 & 0.900 & 1.016 & 2.865 & 1.860 & 2.462 & 2.084 \\
\hline Mapk14 & 1.275 & 1.986 & 1.968 & 0.159 & 0.422 & 0.175 \\
\hline Dusp1 & 3.669 & 1.982 & 1.406 & 10.231 & 4.817 & 2.025 \\
\hline Traf3 & 0.900 & 1.015 & 0.688 & 0.233 & 0.311 & 0.184 \\
\hline Traf6 & 7.377 & 1.440 & 0.671 & 0.040 & 0.430 & 0.176 \\
\hline \multicolumn{7}{|c|}{ INFLAMMASOME } \\
\hline Nirp3 & 0.900 & 0.990 & 0.688 & 0.925 & 0.616 & 0.183 \\
\hline Nirc4 & 0.917 & 1.428 & 0.701 & 0.080 & 0.151 & 0.124 \\
\hline Aim2 & 0.900 & 1.009 & 0.688 & 0.327 & 0.436 & 0.733 \\
\hline Pycard & 0.635 & 1.369 & 0.486 & 0.883 & 3.337 & 1.981 \\
\hline Casp1 & 0.619 & 1.398 & 0.494 & 0.449 & 1.200 & 0.506 \\
\hline \multicolumn{7}{|l|}{ OTHER } \\
\hline Ank1 & 5.078 & 3.958 & 1.936 & 0.111 & 0.588 & 0.353 \\
\hline Epb41 & 1.259 & 1.966 & 0.474 & 0.317 & 0.595 & 0.176 \\
\hline C3 & 0.900 & 0.990 & 0.733 & 5.255 & 9.860 & 1.035 \\
\hline$c 4 b$ & 2.549 & 1.397 & 1.943 & 0.881 & 1.180 & 0.496 \\
\hline$H_{C}$ & 0.880 & 1.016 & 0.673 & 0.057 & 0.211 & 0.088 \\
\hline Casp3 & 0.888 & 0.991 & 0.686 & 0.440 & 1.180 & 0.494 \\
\hline Bax & 0.892 & 0.991 & 0.689 & 0.080 & 0.209 & 0.088 \\
\hline Kras & 1.809 & 1.978 & 1.387 & 0.222 & 0.593 & 0.250 \\
\hline Trp53 & 0.637 & 0.967 & 0.465 & 0.440 & 0.588 & 0.496 \\
\hline Len2 & 0.900 & 1.015 & 91.646 & 83.699 & 111.587 & 46.747 \\
\hline Tfre & 0.879 & 1.398 & 0.700 & 2.559 & 4.823 & 1.435 \\
\hline Nos2 & 5.117 & 3.950 & 1.958 & 0.055 & 0.419 & 0.176 \\
\hline Thbd & 0.895 & 0.988 & 0.687 & 0.019 & 0.070 & 0.124 \\
\hline
\end{tabular}

Genes up-regulated more than 1.3 or down-regulated more than 0.5 are marked in bold.

\section{V. vulnificus Bt2-SerE Is Unable to Overcome Blood Iron Restriction}

This last result (Figure 9A) was surprising as YJ016 was selected as a strain representative of the phylogenetic group with the highest virulent potential for humans (Chen et al., 2003). Thus, we checked the growth ability of both strains in human serum, in the presence and absence of a supplemental iron source. Figure 9B shows that strain YJ016 was equally able to multiply 


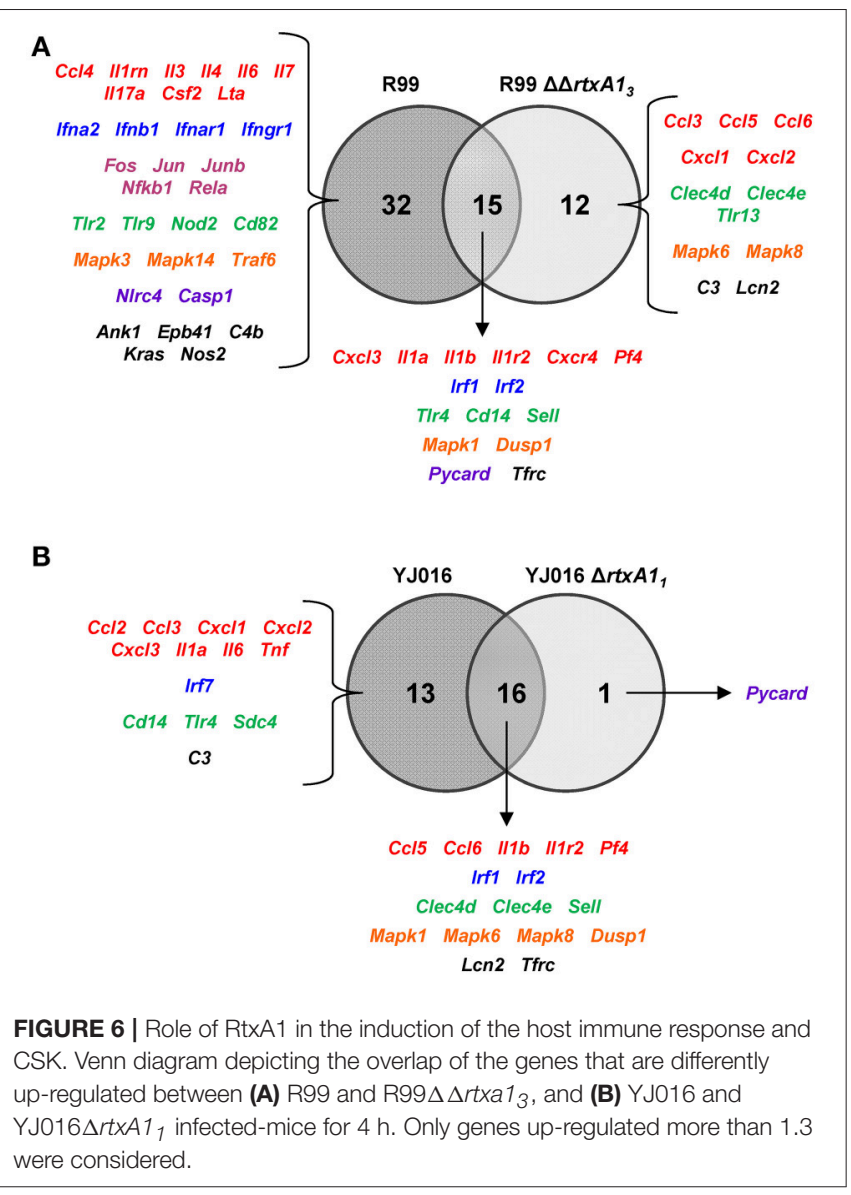

in human serum regardless of the presence of supplemental iron. However, strain R99 was able to grow in the first $2 \mathrm{~h}$ of incubation, but in the absence of supplemental iron its capacity to multiply disappeared. This finding could explain, at least in part, the higher virulence potential of this phylogenetic group, as strain YJ016 could be able to develop sepsis without predisposing conditions (Chen et al., 2003).

\section{DISCUSSION}

The clinical cases of known-etiology associated with the clonal complex V. vulnificus Bt2-SerE correspond to type I human vibriosis after fish handling. The hypothesis underlying the present work refers to the septicemia associated to these vibriosis cases in humans and is based on previous results obtained in the eel which related the RtxA1 3 with animal death by an early peracute septic shock (Lee et al., 2013). Our hypothesis predicted that once the bacterium passes to blood from an infected wound, and only if the bacterium survives in blood, it would produce $\mathrm{RtxA}_{3}$ that would trigger a CKS resulting in human death. A CKS in the context of a bacterial septicemia could be defined as an unbalanced release of pro-inflammatory and anti-inflammatory CKs in response to the pathogen that results in a severe pathological damage (Tisoncik et al., 2012).
We found that, effectively, the infection of mice with a Bt2SerE strain caused a strong and early CKS that was directly related to $\mathrm{RtxAl}_{3}$ as which was not detected in mice infected with the mutant deficient in the toxin. This CKS was also related to mice death, as mice infected with the mutant strain survived despite being colonized by the mutant. In fact, the wild-type strain spread to the bloodstream and overexpressed $r t x A_{3}$ in internal organs as early as $2 \mathrm{hpi}$, inducing the up-regulation of a significant number of immune system-related genes. This result was also obtained in experiments performed in eels (Lee et al., 2013; Callol et al., 2015a; unpublished results), confirming that Bt2SerE exhibits very rapid invasion and $r t x \mathrm{Al}_{3}$ in vivo expression, whatever the infected host is. In accordance again with results reported in eels (Lee et al., 2013; Callol et al., 2015a), the $r t x \mathrm{Al}_{3}$ deficient mutant was able to reach the internal organs (liver and spleen) so the reduction in immune response intensity was not due to a lack of bacterial stimulus. The peak of immune gene activation against the wild-type strain was reached at $4 \mathrm{hpi}$, at which time 47 out of the selected 84 genes were up-regulated while none were down-regulated. At this time, the gene encoding the main hemolysin produced by this species, vvhA, was not induced. This result confirmed that VvhA was not interfering with $\mathrm{RtxA} 1_{3}$, in contrast to that reported in orally Bt1-RtxA $1_{1}$ infected mice where RtxA1 1 and VvhA were found to act together causing pathological damage in the intestine (Jeong and Satchell, 2012).

Interestingly, the CKS induced by $\mathrm{RtxAl}_{3}$ included an upregulation of immune genes related to the response against extracellular and intracellular bacteria. This result was quite unexpected in that all the experiments performed in vivo and in vitro with strain R99, including those performed in the present work, have never suggested the existence of an intracellular stage in the life cycle of this pathogen in any of its hosts. The unexpected up-regulated genes were for: (i) recognition of intracellular pathogens, such as, TLR9 and NOD2; (ii) chemoattraction of macrophages, natural killer cells, and lymphocytes such as, CCL4 (MIP-1 $\beta$; Macrophage inflammatory protein$1 \beta$ ), a gene that was highly activated at all sampling points, and that was also early up-regulated in gills from infected eels (Callol et al., 2015a); (iii) regulatory CK such as, LTA (or TNF- $\beta$ ), IL-17 (implicated in triggering and mediating proinflammatory response, by inducing the expression of different pro-inflammatory CKs, CCs, antimicrobial peptides, growth factors among others); iv) IFN-related genes (associated with $\mathrm{CD}^{+} \mathrm{T}$ cells) such as, ifna2, Ifnb1, Ifnarl, and Ifngr1; (v) CKs involved in the regulation and stimulation of haematopoiesis such as, IL-3, IL-4, IL-7 and CSF2 (this activation could lead to a rapid innate immune system replenishment, exacerbating the inflammatory response); (vi) the inducible NO synthase gene that mediates tumoricidal and bactericidal actions, mainly intracellular (Maeda and Akaike, 1998); and (vii) members of the inflammasome complex such as, NLRC4, PYCARD, and Caspase-1, that have been previously involved in macrophage death by pyroptosis induced by the facultative intracellular pathogen Legionella pneumophila (Case and Roy, 2011; Cerqueira et al., 2015). We also found evidence of a dysregulation of CK production. Thus, DUSP1 (MKP-1) was activated by both 


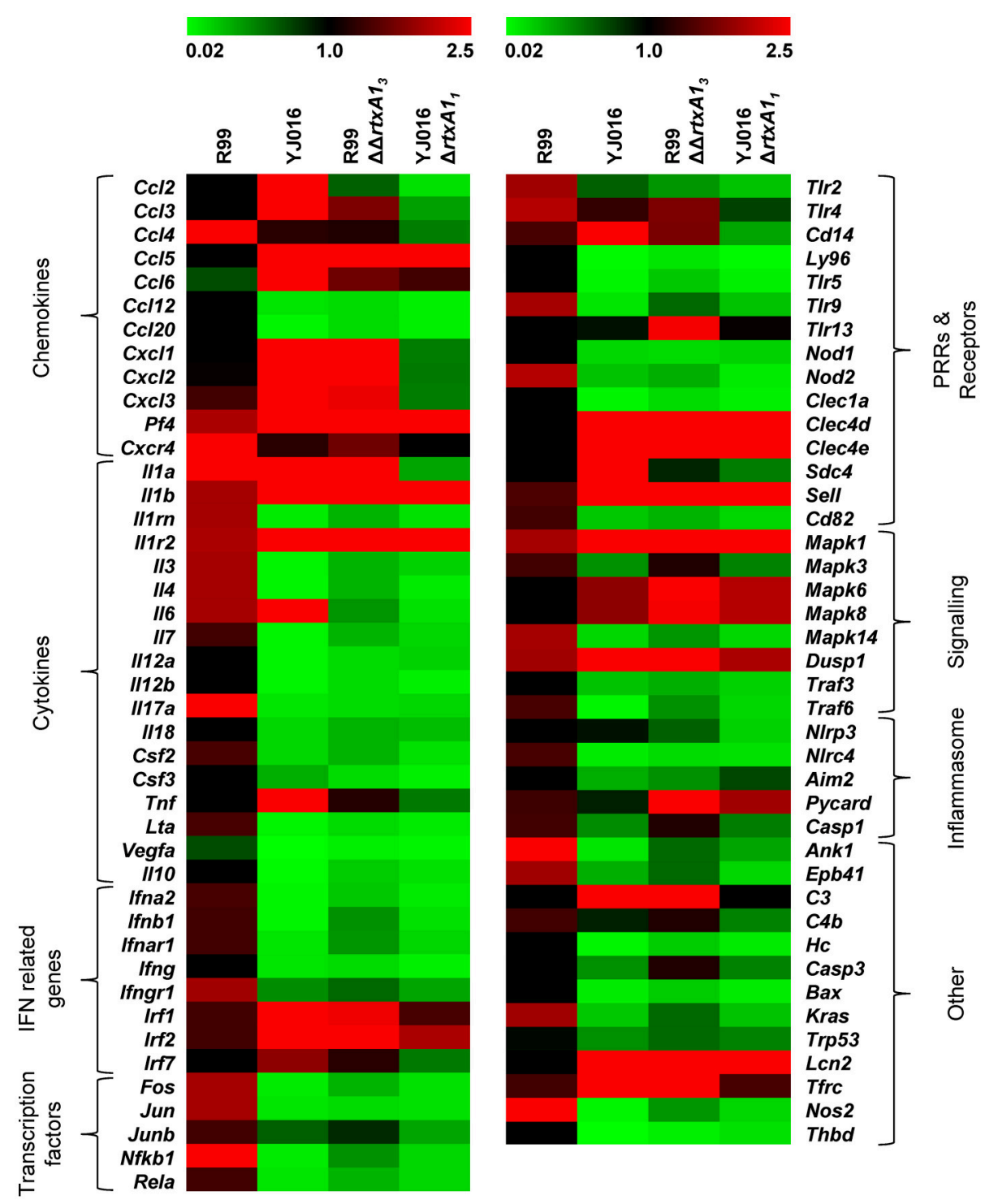

FIGURE 7 | Heat Map. Heat map representing color-coded expression levels of the 84 genes analyzed in infected mice for 4 h with strains Bt2-SerE R99 and Bt1-RtxA1, YJ016, and their derivative RtxA1 mutants. Genes are arranged in functional categories.

strains but was significantly more induced by YJ016 (Table 2). MKP-1 regulates, via dephosphorylation, the activation of several MAPK including $\mathrm{p} 38$, thus limiting their signaling potential and the production of pro-inflammatory CKs (Zhao et al., 2006; Wang and Liu, 2007; Moyes et al., 2010). In agreement with the pattern of DUSP1 activation, the Mapk14 gene (or p38 $\alpha$ ) was up-regulated by the Bt2-SerE strain, but down-regulated by the selected Bt1-RtxA $1_{1}$ strain. In contrast, mice infected with the Bt1-RtxA1 1 -strain developed a typical immune response against an extracellular pathogen: most of the CKS genes were downregulated in these mice while genes known to have a beneficial role during extracellular bacterial infections (Il6, Tnf or Lcn2) were clearly up-regulated (Shin et al., 2002; Berger et al., 2006; Goo et al., 2007; Chuang et al., 2010). Finally, we also found that the Bt1-RtxA1 $1_{1}$ strain induced high levels of the CCs Ccl3 and
Cxcl1. CXCL1 has been recently proven to play a crucial role in the inflammatory response developed against Bt1 V. vulnificus infection by reducing hepatic injury (Liu et al., 2015). In contrast, the Bt2-SerE strain only induced these CC at lower levels at $6 \mathrm{hpi}$, which could contribute to the severity of the disease.

By comparing the immune responses against Bt1-RtxA $1_{1}$ and Bt2-SerE strains we can predict that the common response against any $V$. vulnificus strain would involve, at least, the activation of a series of genes related to LPS recognition (Tlr4 and Cd14) (Kawai and Akira, 2009) together with several genes for the IL-1 family (Illa, Illb, Il1r2), IL-6, and Pf4 as well as Tfrc. Previous works performed with Bt1 strains had already highlighted the important role of TLR4, IL-1 $\alpha$, IL-1 $\beta$, IL-6, CXCL1, or CCL3 in the response against V. vulnificus (Shin et al., 2002; Chuang et al., 2010; Stamm, 2010; Mayer et al., 2014; Liu 


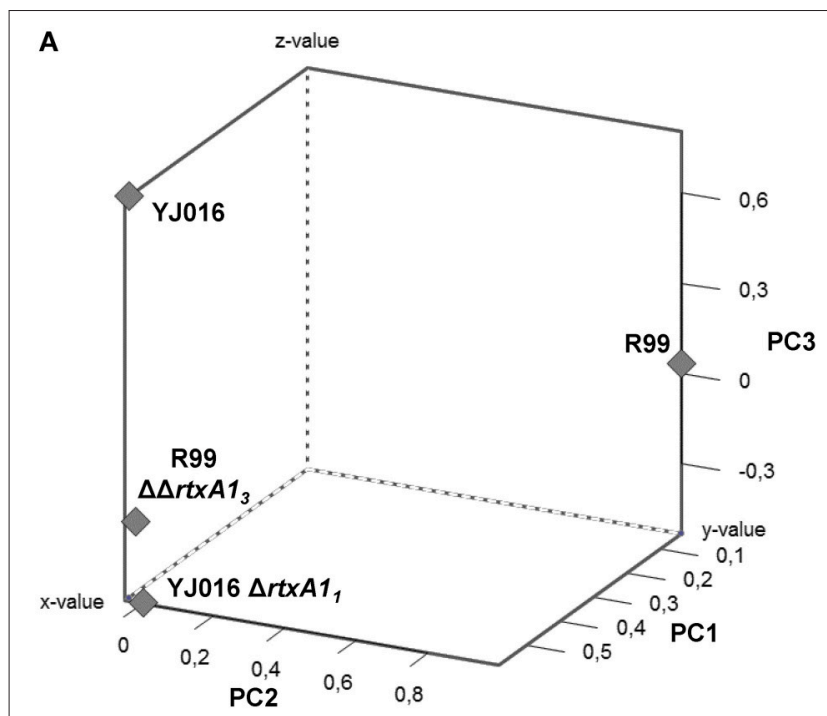

B

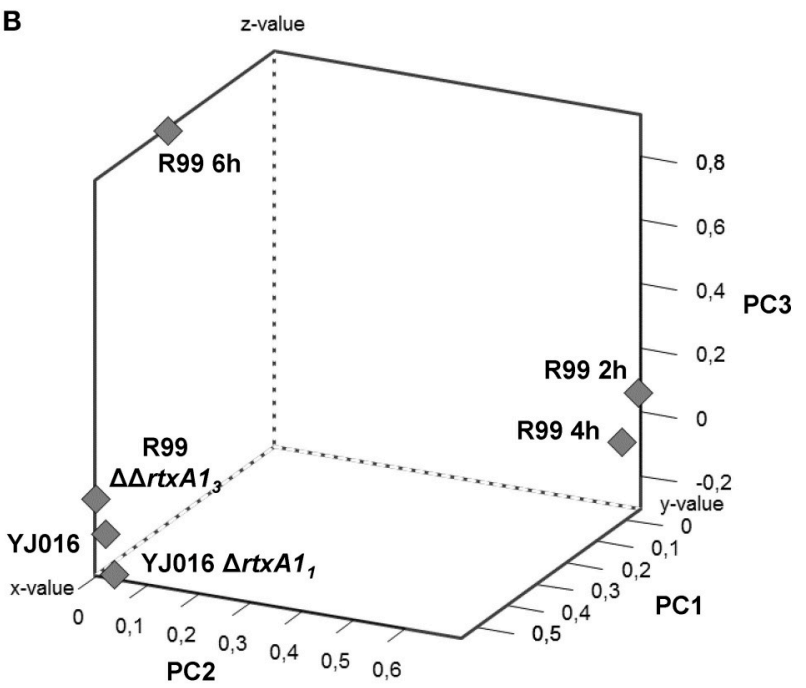

FIGURE 8 | Principal Component Analysis (PCA) 3-D plot of the gene expression. Three principal components are represented, PC1 on X-axis, PC2 on Y-axis, and PC3 on Z-axis. (A) shows the analysis of mice infected for $4 \mathrm{~h}$ with the wild-type strains and their derivative RtxA1 mutants. In (B) mice infected with the Bt2-SerE R99 strain for 2 and 6 h were included in the analysis.

et al., 2015). However, none of them had reported the activation of either Tfrc, a gene encoding a cell surface receptor necessary for transferrin recycling and iron uptake, or Pf4. Transferrin is one of the acute-phase proteins that are produced by the liver in response to extracellular bacterial infections, which in turn produce iron-sequestering and a nutritional immunity (Parrow et al., 2013). The activation of Tfrc by blood cells would be an indirect signal that transferrin is being produced by the liver. Pf4, which was by far the most up-regulated gene by the Bt1 strain, is released by activated platelets, binds to the bacterial surface inducing the formation of neoepitopes, and facilitates bacterial clearance (Krauel et al., 2011). Specifically, PF4 binds

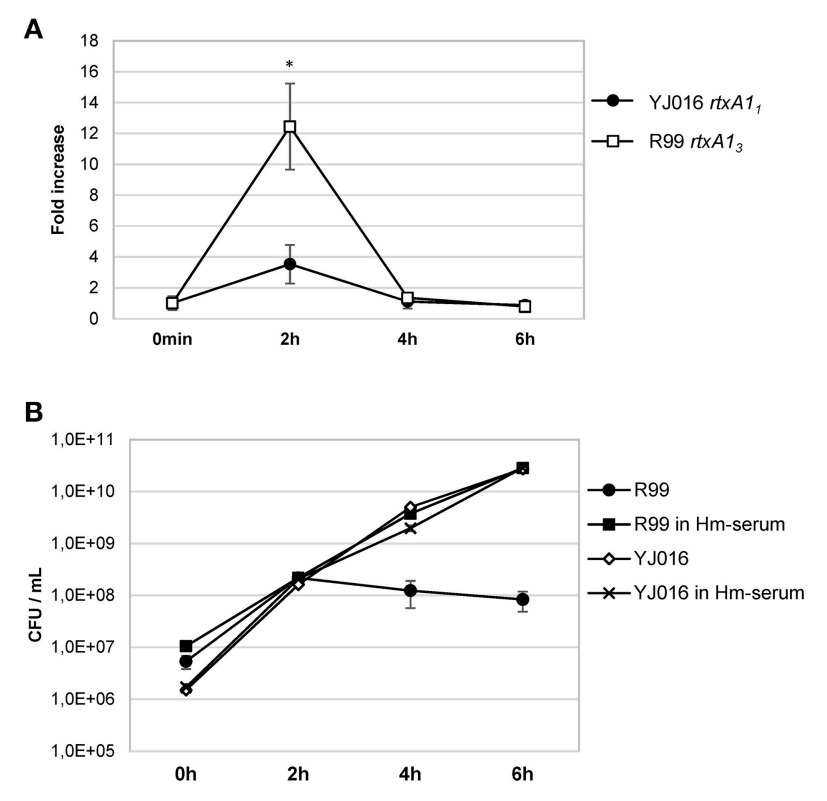

FIGURE 9 | rtxA1 expression in the presence of human blood cells. (A) Expression by Real time qPCR of $r$ txA1 1 and $r$ txA $1_{3}$ in YJ016 and R99 strains, respectively. Bacteria were incubated for $0,2,4$, and $6 \mathrm{~h}$ in commercial human serum supplemented with Fe (Hm-serum) plus human PBMCs. The value of expression of each gene in the $0 \mathrm{~h}$ sample was set equal to 1 , and the fold-change in gene expression was calculated in 2, 4, and 6 h samples. (B) Bacterial growth in commercial human serum with (Hm-serum) or without supplemented Fe. (A, B) Data represent mean values \pm standard deviation from two independent experiments. The significance of the differences was determined using Student's two-tailed $t$-test; ${ }^{*} p<0.05$ compared with values at time $\mathrm{Oh}$.

to negatively charged LPS on gram-negative bacteria (Krauel et al., 2012). Our results further support the hypothesis that neoepitope formation by PF4 after binding to bacteria is an ancient and early host defense mechanism against extracellular pathogens (Krauel et al., 2012). Nevertheless, both tested $V$. vulnificus strains are encapsulated (Valiente et al., 2008a) and capsule would be expected to interfere with PF4 deposition on LPS, partially explaining why capsulated $V$. vulnificus strains are significantly more virulent than acapsulated ones (Simpson et al., 1987; Strom and Paranjpye, 2000).

Further, we analyzed the immune response pattern by PCA analysis and found that Bt1-RtxA $1_{1}$ and Bt2-SerE MARTX mutants grouped together and close to the Bt1-RtxA1 $1_{1}$ strain. This proximity in immune response was highlighted even more when the data from R99-infected mice at 2 and 6 hpi were introduced in the analysis; three clusters were observed, one formed by both mutants and the Bt1-RtxA1 1 strain, another by the samples taken at 2 and 4 hpi from Bt2-SerE-infected mice, and the third with an intermediate position formed from the sample taken at $6 \mathrm{hpi}$. This finding also suggested that the CKS induced by Bt2-SerE presents a peak very early, at $4 \mathrm{hpi}$ and decreasing at $6 \mathrm{~h}$, a model that is compatible with data of the death dynamic of mice after i.p. infection with Bt2-SerE; most mice either die before 8 hpi or survive the infection. 
We had previously demonstrated that V. vulnificus Bt2-SerE induced death by lysis of endothelial cells and by apoptosis of human monocytes (Murciano et al., 2015). In our present work, we linked both activities with $\operatorname{RtxA} 1_{3}$, which suggests that this toxin can induce cell death by different mechanisms depending on the target cell. RtxA1 $1_{3}$ differs from the other MARTX $\mathrm{Vv}_{\mathrm{Vv}}$ in that possesses a copy of an ACD domain, in common with MARTX of $V$. cholerae, and two copies of the MCF domain, a domain also present in other MARTX $_{\mathrm{V}_{\mathrm{v}}}$ but in only one copy (Lee et al., 2007; Liu et al., 2007; Kim et al., 2008, 2015; Kwak et al., 2011; Lo et al., 2011; Roig et al., 2011; Jeong and Satchell, 2012; Satchell, 2015). Moreover, all the Bt2-SerE strains possess two identical copies of $r t x A_{3}$, one in chromosome II and another in the virulence plasmid pVvBt2 (Roig et al., 2011). Thus, we tested if the ACD domain in $\mathrm{RtxA}_{3}$ was also capable of polymerizing actin and found that this domain effectively caused a strong and rapid actin oligomerization in vitro in both cell types. However, the ACD domain was not revealed as essential for apoptosis of monocytes in vitro, suggesting that the apoptotic activity on monocytes probably was caused by MCF domains present as four copies per bacterium. In partial accordance, it was previously described that MCF domains on other MARTX $\mathrm{Vv}_{\mathrm{v}}$ induce the intrinsic pathway of apoptosis (Agarwal et al., 2015b).

Looking in depth the immune-pattern specific for $\mathrm{RtxA}_{3}$ and the mode of action of this toxin, we conclude that, whatever the attacked cell is, either the toxin facilitates bacterial invasion or, alternatively, the toxin by itself activates an immune response that, at least to some extent, is similar to that produced against intracellular pathogens like L. pneumophila. Regarding the first possibility, we have never seen bacteria inside eukaryotic cells either in the experiments performed in previous works or in these experiments. We tested the second possibility in vitro by infecting the two human cell lines with R99 and its mutant and analyzing the expression of selected CK and CC genes. Regrettably, cells infected with the wild-type strain died early, which resulted in an apparently stronger immune response against the mutant (results not shown), and suggesting that this in vitro approach was not adequate to test the hypothesis. In any case and whatever the CKS-activation mechanism is, the fact that this toxin is linked to this storm is exciting, as $\mathrm{RtxA} 1_{3}$ could be representative of a new family of toxins able to trigger a life threatening immuneresponse. Figure 10 summarizes a hypothetical model for sepsis induced by $\mathrm{RtxA}_{3}$ in which we propose that not only blood cells but also endothelial cells would be involved. Previously we had demonstrated that endothelial cells can produce, in vitro, multiple inflammatory mediators when they are infected with V. vulnificus Bt2-SerE (Murciano et al., 2015) This would enhance the destructive effect on mediators liberated by blood cells. Finally, we discarded the possibility that this early CKS was due to bacterial growth in blood; bacteria were present in internal organs of infected mice below the detection limit $(<10 \mathrm{CFU} / \mathrm{mL})$ since they could be only recovered after enrichment.

Our next step was to find out if rtxA1 would be expressed in humans by using an ex vivo model of infection. We found that both $r t x A 1_{3}$ and $r t x A 1_{1}$ were highly expressed at 2 hpi in human blood, confirming the results obtained in the mouse. We completed these experiments by growing the bacteria in normal and hm-serum. Interestingly, the Bt2-SerE strain was only able to grow in hm-serum while YJ016 grew in both normal and hm-serum. It is generally assumed that $V$. vulnificus is only able to cause death by sepsis in patients with high iron-levels in blood, although there are a few clinical cases of sepsis in healthy patients described in the literature. YJ016 was selected for the study because it is representative of the phylogenetic lineage that groups the most virulent Bt1 strains, most of them linked to primary septicaemia after raw seafood ingestion (Cohen et al., 2007; Sanjuán et al., 2011). According to our results, YJ016 would also be representative of the group of $V$. vulnificus strains able to cause sepsis in healthy patients.

Epidemiological data reveal that the number of cases of sepsis caused by Bt1 strains is by far much higher than those caused by $\mathrm{Bt} 2$-SerE, which never has been linked to primary sepsis after oyster ingestion. These data could lead us to underestimate the public health danger that represents this zoonotic group. In fact, a clinical Bt1 strain has been shown to carry an RtxA1 toxin with the same domain organization as the Bt2-SerE strain, although that strain only had the chromosomal copy of the toxin as it did not have any plasmids (Kwak et al., 2011). This further demonstrates the risk potential of $\mathrm{RtxA}_{3}$ for humans. At the moment, it seems that its geographical distribution is more restricted (Amaro et al., 2015), and its apparent inability to colonize oysters (Amaro et al., 2015) prevents it from being associated with a higher number of clinical cases.

$V$. vulnificus Bt 2 shows an extraordinary ability to adapt to the environment, i.e., after substituting saline water by freshwater in eel-farms to control vibriosis, a new Bt2-serovar, able to survive and infect in freshwater, emerged in $<5$ years (Fouz et al., 2006). Climate change is increasing water temperature and decreasing water salinity, which could extend the geographical distribution of Bt2-SerE and increase the probability of contact with its intermediate reservoir, oysters, and with its end host, humans. This fact together with the fast adaptation of this Bt to external changes suggests a complicated picture for the next years.

In conclusion, for the first time, and by using a murine model of infection, we have demonstrated that the sepsis from vibrosis caused by the Bt2-SerE of $V$. vulnificus could occur through the type III MARTX $\mathrm{Vv}_{\mathrm{v}}$ toxin, which induces an erroneous and dysregulated immune response that would lead to a rapid CKS and, in the end, to death of its host. The specific pattern of the immune response associated to this CKS revealed that the pathogen has either an unknown intra-cellular life stage or, which seems more probable, that the toxin triggers a lifethreatening immune response after attacking different immune cells. Although the precise molecular mechanism for the toxic action remains to be determined, we predict that the toxigenic potential of $\mathrm{RtxAl}_{3}$ is probably not due to the effect of a single domain (ACD vs. MCF) but to the unique combination of domains $(\mathrm{ACD}+2 \mathrm{MCF})$ along with duplication of the gene in the bacterium. This statement is based on previous results obtained with a different mouse strain in which we found that deletion of only one copy of the $r x x 1_{3}$ gene, either the plasmidic or the chromosomic one, only reduced virulence by 1-log (Lee et al., 2013), and on the results shown here, the expression level of $r x \mathrm{~A}_{3}$ in human blood being four times the expression level 


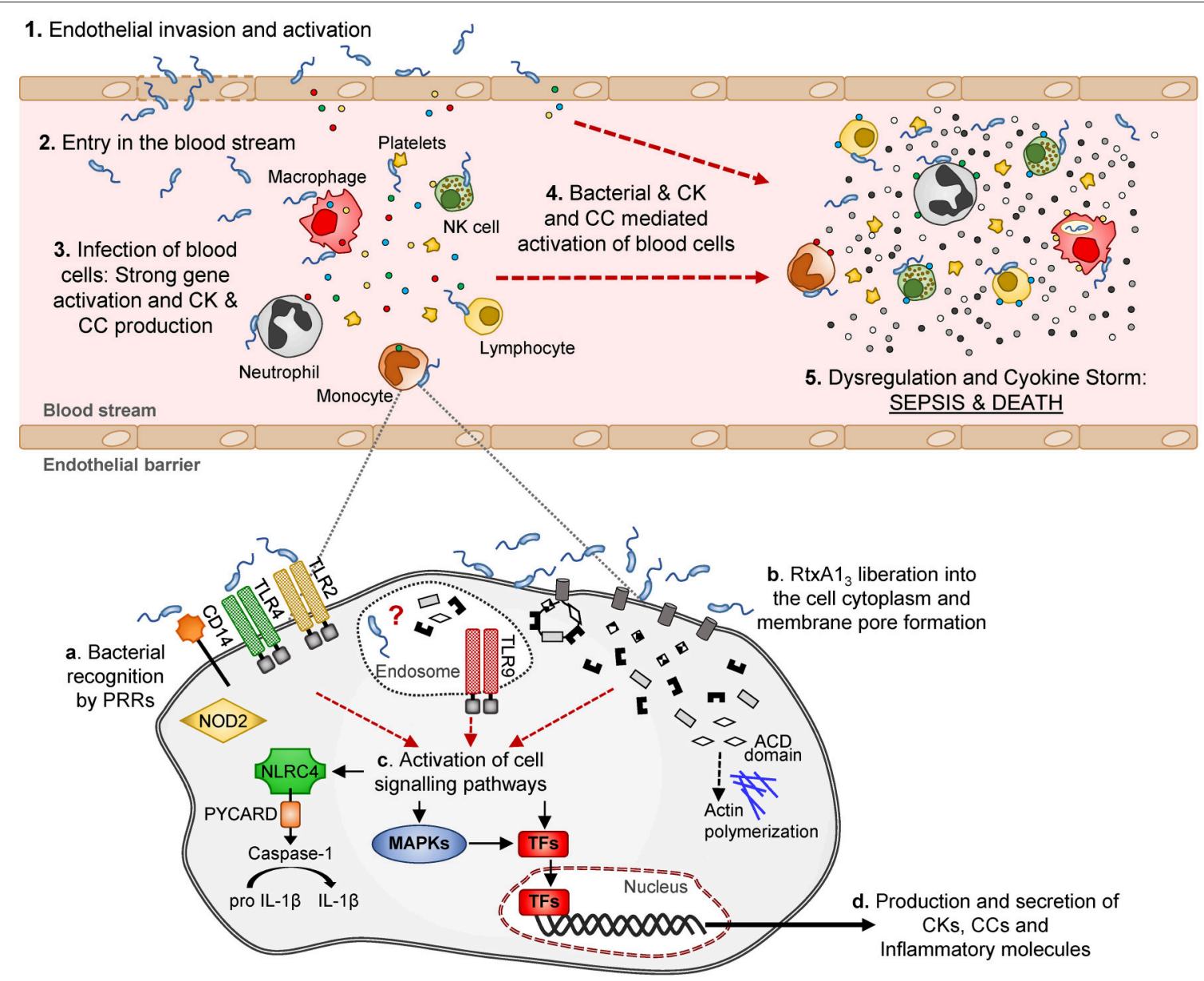

FIGURE 10 | Schematic model of $V$. vulnificus Bt2-SerE induced sepsis. V. vulnificus Bt2-SerE would cause sepsis only in patients with high iron levels in blood, and according to the following model: (1) the bacterial cells would reach the endothelial microvasculature from the infection site. There, they will infect the endothelial cells, producing RtxA1 3 that would enter the host cell and cause death by lysis, allowing the bacterium to invade the blood stream (2). (3) There, the bacterial cells, in low number, would interact with different types of immune blood cells. Once in contact, the bacteria would produce and again liberate RtxA $1_{3}$ into the host cell cytoplasm (see detail in the lower part of the figure). This toxin, together with a superficial recognition of bacterial cells by extracellular and intracellular receptors, would induce activation of different signaling pathways and transcription factors that in turn would produce the activation of apoptosis and/or inflammasome and the secretion of CKs, CCs, and other immune mediators. Although, intracellular receptors are activated, it is not clear if the bacterium is able to enter into the cell cytoplasm or if this activation is triggered by $\mathrm{RtXA1}{ }_{3}$ domains or other bacterial components. Thus, the hypothetic intra-cellular life style of $V$. vulnificus Bt2-SerE and/or the mechanism for this anomalous immune response activation remains to be investigated. (4) The inflammatory proteins in response to the infection would recruit and activate additional immune cells. These new cells, which could also be infected with bacteria, would be activated to such a great extent that they will suffer gene dysregulation and a CSK would start, which in turn would produce the host's death by sepsis (5).

of $r x A 1_{1}$. Finally, even though the clinical signs of sepsis caused by Bt1-RtxA $1_{1}$ and Bt2-SerE could converge, the mechanisms by which death occurs would be different. Bt2-SerE would induce a dysregulated immune response and a septic shock in which RtxA $1_{3}$ would be critical, while the sepsis caused by Bt1-RtxA1 would be similar to that induced by other gram-negative bacteria, being linked to growth in blood and LPS liberation (Opal, 2010; Ramachandran, 2014).

\section{AUTHOR CONTRIBUTIONS}

CL and TH obtained the mutants and characterized them genetiaclly and phenotypically under the supervision of LH. CM and CA designed the experimental work to test the hypothesis.
CM carried out the in vitro (assisted by $\mathrm{AF}$ ), ex vivo and in vivo (assisted by $\mathrm{BF}$ ) experiments under the supervision of $\mathrm{CA}$. CM analyzed the results obtained with the appropriate software. CM, CA, and $\mathrm{LH}$ discussed the results obtained. CM wrote the draft of the paper, CA corrected the draft and wrote the final version with the final consensus of all the authors.

\section{ACKNOWLEDGMENTS}

The authors thank the SCSIE of the University of Valencia for technical support. Specially, we would like to thank Vicente Sentandreu and Amparo Martinez for their help for the bioinformatic analysis, Inmaculada Noguera and Amparo 
Llorens for help with the animal work, and Ana Flores for the flow cytometry support. We also want to thank Dr. Arraztio (Tebu-bio) for her technical support in the generation of the qPCR arrays and to the blood donors that contributed to this work. Special thanks to Dr. James Oliver for reviewing the MS. This work has been financed by grants AGL2014-58933-P from MINECO (Spain) and NSC 100-2320-B-006 -012-MY3 from the Ministry of Science and Technology (Taiwan). CM was supported

\section{REFERENCES}

Agarwal, S., Kim, H., Chan, R. B., Agarwal, S., Williamson, R., Cho, W., et al. (2015a). Autophagy and endosomal trafficking inhibition by Vibrio cholerae MARTX toxin phosphatidylinositol-3-phosphate-specific phospholipase A1 activity. Nat. Commun. 6:8745. doi: 10.1038/ncomms9745

Agarwal, S., Zhu, Y., Gius, D. R., and Satchell, K. J. F. (2015b). The Makes Caterpillars Floppy (MCF)-like domain of Vibrio vulnificus induces mitochondrion-mediated apoptosis. Infect. Immun. 83, 4392-4403. doi: 10.1128/IAI.00570-15

Amaro, C., and Biosca, E. G. (1996). Vibrio vulnificus biotype 2, pathogenic for eels, is also an opportunistic pathogen for humans. Appl. Environ. Microbiol. $62,1454-1457$.

Amaro, C., Sanjuán, E., Fouz, B., Pajuelo, D., Lee, C.-T., Hor, L.-I., et al. (2015). The fish pathogen vibrio vulnificus biotype 2: epidemiology, phylogeny, and virulence factors involved in warm-water vibriosis. Microbiol. Spectr. 3, 1-23. doi: 10.1128/microbiolspec.VE-0005-2014

Antic, I., Biancucci, M., Zhu, Y., Gius, D. R., and Satchell, K. J. F. (2015). Sitespecific processing of Ras and Rap1 switch I by a MARTX toxin effector domain. Nat. Commun. 6:7396. doi: 10.1038/ncomms8396

Arezes, J., Jung, G., Gabayan, V., Valore, E., Ruchala, P., Gulig, P. A., et al. (2015). Hepcidin-induced hypoferremia is a critical host defense mechanism against the siderophilic bacterium Vibrio vulnificus. Cell Host Microbe 17, 47-57. doi: 10.1016/j.chom.2014.12.001

Bacon, B. R., Adams, P. C., Kowdley, K. V., Powell, L. W., and Tavill, A. S. (2011). Diagnosis and management of hemochromatosis: 2011 practice guideline by the American Association for the study of liver diseases. Hepatology 54, 328-343. doi: 10.1002/hep. 24330

Baker-Austin, C., Trinanes, J. A., Taylor, N. G. H., Hartnell, R., Siitonen, A., and Martinez-Urtaza, J. (2012). Emerging Vibrio risk at high latitudes in response to ocean warming. Nat. Clim. Change 3, 73-77. doi: 10.1038/nclimate1628

Berger, T., Togawa, A., Duncan, G. S., Elia, A. J., You-Ten, A., Wakeham, A., et al. (2006). Lipocalin 2-deficient mice exhibit increased sensitivity to Escherichia coli infection but not to ischemia-reperfusion injury. Proc. Natl. Acad. Sci. U.S.A. 103, 1834-1839. doi: 10.1073/pnas.0510847103

Bisharat, N., Agmon, V., Finkelstein, R., Raz, R., Ben-Dror, G., Lerner, L., et al. (1999). Clinical, epidemiological, and microbiological features of Vibrio vulnificus biogroup 3 causing outbreaks of wound infection and bacteraemia in Israel. Lancet 354, 1421-1424. doi: 10.1016/S0140-6736(99)02471-X

Callol, A., Pajuelo, D., Ebbesson, L., Teles, M., MacKenzie, S., and Amaro, C. (2015a). Early steps in the European eel (Anguilla anguilla)-Vibrio vulnificus interaction in the gills: role of the RtxA13 toxin. Fish Shellfish Immunol. 43, 502-509. doi: 10.1016/j.fsi.2015.01.009

Callol, A., Reyes-López, F. E., Roig, F. J., Goetz, G., Goetz, F. W., Amaro, C., et al. (2015b). An enriched European eel transcriptome sheds light upon host-pathogen interactions with Vibrio vulnificus. PLoS One 10:e133328. doi: 10.1371/journal.pone.0133328

Case, C. L., and Roy, C. R. (2011). Asc modulates the function of NLRC4 in response to infection of macrophages by Legionella pneumophila. MBio 2:e0117-11. doi: 10.1128/mBio.00117-11

Cerqueira, D. M., Pereira, M. S. F., Silva, A. L. N., Cunha, L. D., and Zamboni, D. S. (2015). Caspase-1 but not caspase-11 Is required for NLRC4mediated pyroptosis and restriction of infection by Flagellated legionella species in mouse Macrophages and in vivo. J. Immunol. 195, 2303-2311. doi: 10.4049/jimmunol.1501223 by a "Juan de la Cierva" postdoctoral fellowship granted by MINECO (Spain).

\section{SUPPLEMENTARY MATERIAL}

The Supplementary Material for this article can be found online at: http://journal.frontiersin.org/article/10.3389/fcimb. 2017.00332/full\#supplementary-material

Chen, C.-Y., Wu, K.-M., Chang, Y.-C., Chang, C.-H., Tsai, H.-C., Liao, T.-L., et al. (2003). Comparative genome analysis of Vibrio vulnificus, a marine pathogen. Genome Res. 13, 2577-2587. doi: 10.1101/gr.1295503

Chuang, C.-C., Chuang, Y.-C., Chang, W.-T., Chen, C.-C., Hor, L.-I., Huang, A.M., et al. (2010). Macrophage migration inhibitory factor regulates interleukin6 production by facilitating nuclear factor-kappa B activation during Vibrio vulnificus infection. BMC Immunol. 11:50. doi: 10.1186/1471-2172-11-50

Cohen, A. L. V., Oliver, J. D., DePaola, A., Feil, E. J., and Boyd, E. F. (2007). Emergence of a virulent clade of Vibrio vulnificus and correlation with the presence of a 33-kilobase genomic island. Appl. Environ. Microbiol. 73, 5553-5565. doi: 10.1128/AEM.00635-07

Dolores, J. S., Agarwal, S., Egerer, M., and Satchell, K. J. F. (2015). Vibrio cholerae MARTX toxin heterologous translocation of beta-lactamase and roles of individual effector domains on cytoskeleton dynamics. Mol. Microbiol. 95, 590-604. doi: 10.1111/mmi.12879

Feldhusen, F. (2000). The role of seafood in bacterial foodborne diseases. Microbes Infect. 2, 1651-1660. doi: 10.1016/S1286-4579(00)01321-6

Fouz, B., Larsen, J. L., and Amaro, C. (2006). Vibrio vulnificus serovar A: an emerging pathogen in European anguilliculture. J. Fish Dis. 29, 285-291. doi: 10.1111/j.1365-2761.2006.00719.x

Fullner Satchell, K. J. (2007). MARTX, multifunctional autoprocessing repeats-intoxin toxins. Infect. Immun. 75, 5079-5084. doi: 10.1128/IAI.00525-07

Goo, S. Y., Han, Y. S., Kim, W. H., Lee, K.-H. H., Park, S.-J. J., Sung, Y. G., et al. (2007). Vibrio vulnificus IlpA-induced cytokine production is mediated by Tolllike receptor 2. J. Biol. Chem. 282, 27647-27658. doi: 10.1074/jbc.M701876200

Hammer, Ø., Harper, D. A. T., and Ryan, P. D. (2001). PAST: Paleontological statistics software package for education and data analysis. Palaeontol. Electron. 4, 1-9. doi: 10.1016/j.bcp.2008.05.025

Hanahan, D. (1983). Studies on transformation of Escherichia coli with plasmids. J. Mol. Biol. 166, 557-580. doi: 10.1016/S0022-2836(83)80284-8

Hor, L. I., Chang, Y. K., Chang, C. C., Lei, H. Y., and Ou, J. T. (2000). Mechanism of high susceptibility of iron-overloaded mouse to Vibrio vulnificus infection. Microbiol. Immunol. 44, 871-878. doi: 10.1111/j.1348-0421.2000.tb02577.x

Horseman, M. A., and Surani, S. (2011). A comprehensive review of Vibrio vulnificus: an important cause of severe sepsis and skin and soft-tissue infection. Int. J. Infect. Dis. 15, e157-e166. doi: 10.1016/j.ijid.2010.11.003

Jeong, H. G., and Satchell, K. J. F. (2012). Additive function of Vibrio vulnificus MARTXVv and VvhA cytolysins promotes rapid growth and epithelial tissue necrosis during intestinal infection. PLoS Pathog. 8:e1002581. doi: 10.1371/journal.ppat.1002581

Jones, M. K., and Oliver, J. D. (2009). Vibrio vulnificus: disease and pathogenesis. Infect. Immun. 77, 1723-1733. doi: 10.1128/IAI.01046-08

Kawai, T., and Akira, S. (2009). The roles of TLRs, RLRs and NLRs in pathogen recognition. Int. Immunol. 21, 317-337. doi: 10.1093/intimm/dxp017

Kim, B. S., Gavin, H. E., and Satchell, K. J. F. (2015). Distinct roles of the repeat-containing regions and effector domains of the Vibrio vulnificus multifunctional-autoprocessing repeats-in-toxin (MARTX) toxin. MBio 2:e00324-15. doi: 10.1128/mBio.00324-15

Kim, Y. R., Lee, S. E., Kook, H., Yeom, J. A., Na, H. S., Kim, S. Y., et al. (2008). Vibrio vulnificus RTX toxin kills host cells only after contact of the bacteria with host cells. Cell. Microbiol. 10, 848-862. doi: 10.1111/j.1462-5822.2007.01088.x

Krauel, K., Pötschke, C., Weber, C., Kessler, W., Fürll, B., Ittermann, T., et al. (2011). Platelet factor 4 binds to bacteria-inducing antibodies cross-reacting with the major antigen in heparin-induced thrombocytopenia. Blood 117, 1370-1378. doi: 10.1182/blood-2010-08-301424 
Krauel, K., Weber, C., Brandt, S., Zähringer, U., Mamat, U., Greinacher, A., et al. (2012). Platelet factor 4 binding to lipid A of Gram-negative bacteria exposes PF4/heparin-like epitopes. Blood 120, 3345-3352. doi: 10.1182/blood-2012-06-434985

Kwak, J. S., Jeong, H.-G., and Satchell, K. J. F. (2011). Vibrio vulnificus rtxAl gene recombination generates toxin variants with altered potency during intestinal infection. Proc. Natl. Acad. Sci. U.S.A. 108, 1645-1650. doi: $10.1073 /$ pnas. 1014339108

Lee, C. T., Amaro, C., Wu, K. M., Valiente, E., Chang, Y. F., Tsai, S. F., et al. (2008). A common virulence plasmid in biotype 2 Vibrio vulnificus and its dissemination aided by a conjugal plasmid. J. Bacteriol. 190, 1638-1648. doi: 10.1128/JB.01484-07

Lee, C. T., Pajuelo, D., Llorens, A., Chen, Y. H., Leiro, J. M., Padrós, F., et al. (2013). MARTX of Vibrio vulnificus biotype 2 is a virulence and survival factor. Environ. Microbiol. 15, 419-432. doi: 10.1111/j.1462-2920.2012.02854.x

Lee, J. H., Kim, M. W., Kim, B. S., Kim, S. M., Lee, B. C., Kim, T. S., et al. (2007). Identification and characterization of the Vibrio vulnificus rtxA essential for cytotoxicity in vitro and virulence in mice. J. Microbiol. 45, 146-152.

Liu, M., Alice, A. F., Naka, H., and Crosa, J. H. (2007). The HlyU protein is a positive regulator of rtxAl, a gene responsible for cytotoxicity and virulence in the human pathogen Vibrio vulnificus. Infect. Immun. 75, 3282-3289. doi: 10.1128/IAI.00045-07

Liu, X. F., Wu, J., Wang, M. Y., Chen, Y. J., Cao, Y., and Hu, C. J. (2015). Identification of novel inflammatory cytokines and contribution of keratinocyte-derived chemokine to inflammation in response to Vibrio vulnificus infection in mice. Inflammation 38, 1864-1873. doi: 10.1007/s10753-015-0166-5

Lo, H. R., Lin, J. H., Chen, Y. H., Chen, C. L., Shao, C. P., Lai, Y. C., et al. (2011). RTX toxin enhances the survival of Vibrio vulnificus during infection by protecting the organism from phagocytosis. J. Infect. Dis. 203, 1866-1874. doi: 10.1093/infdis/jir070

Maeda, H., and Akaike, T. (1998). Nitric oxide and oxygen radicals in infection, inflammation, and cancer. Biochemistry 63, 854-865. doi: $10.1007 / 978-1-4615-5081-5 \_18$

Mayer, A. M. S., Hall, M. L., Holland, M., De Castro, C., Molinaro, A., Aldulescu, M., et al. (2014). Vibrio vulnificus MO6-24/O lipopolysaccharide stimulates superoxide anion, thromboxane B2, matrix metalloproteinase-9, cytokine and chemokine release by rat brain microglia in vitro. Mar. Drugs 12, 1732-1756. doi: $10.3390 / \mathrm{md} 12041732$

Moyes, D. L., Runglall, M., Murciano, C., Shen, C., Nayar, D., Thavaraj, S., et al. (2010). A biphasic innate immune MAPK response discriminates between the yeast and hyphal forms of Candida albicans in epithelial cells. Cell Host Microbe 8, 225-235. doi: 10.1016/j.chom.2010.08.002

Murciano, C., Hor, L.-I., and Amaro, C. (2015). Host-pathogen interactions in Vibrio vulnificus: responses of monocytes and vascular endothelial cells to live bacteria. Future Microbiol. 10, 471-487. doi: 10.2217/fmb.14.136

Oliver, J. D. (2015). The biology of Vibrio vulnificus. Microbiol. Spectr. 3, 1-10. doi: 10.1128/microbiolspec.VE-0001-2014

Opal, S. M. (2010). "Endotoxins and other sepsis triggers," in Endotoxemia and Endotoxin Shock: Disease, Diagnosis and Therapy, eds C. Ronco, P. Piccinni and M. H. Rosner (Basel: Karger), 14-24.

Parrow, N. L., Fleming, R. E., and Minnick, M. F. (2013). Sequestration and scavenging of iron in infection. Infect. Immun. 81, 3503-3514. doi: 10.1128/IAI.00602-13

Philippe, N., Alcaraz, J. P., Coursange, E., Geiselmann, J., and Schneider, D. (2004). Improvement of pCVD442, a suicide plasmid for gene allele exchange in bacteria. Plasmid 51, 246-255. doi: 10.1016/j.plasmid.2004.02.003

Ramachandran, G. (2014). Gram-positive and gram-negative bacterial toxins in sepsis: a brief review. Virulence 5, 213-218. doi: 10.4161/viru.27024

Reed, L. J., and Muench, H. (1938). A simple method of estimating fifty per cent endpoints. Am. J. Hyg. 27, 493-497.

Roig, F. J., González-Candelas, F., and Amaro, C. (2011). Domain organization and evolution of multifunctional autoprocessing repeats-in-toxin (MARTX) toxin in Vibrio vulnificus. Appl. Environ. Microbiol. 77, 657-668. doi: 10.1128/AEM.01806-10

Sandset, P. M. (2012). PL-20 CXCL4-platelet factor 4, heparin-induced thrombocytopenia and cancer. Thromb. Res. 129, S97-S100. doi: 10.1016/S 0049-3848(12)70026-9
Sanjuán, E., González-Candelas, F., and Amaro, C. (2011). Polyphyletic origin of Vibrio vulnificus biotype 2 as revealed by sequence-based analysis. Appl. Environ. Microbiol. 77, 688-695. doi: 10.1128/AEM. 01263-10

Satchell, K. J. F. (2011). Structure and function of MARTX toxins and other large repetitive RTX proteins. Annu. Rev. Microbiol. 65, 71-90. doi: 10.1146/annurev-micro-090110-102943

Satchell, K. J. F. (2015). Multifunctional-autoprocessing repeats-in-toxin (MARTX) toxins of vibrios. Microbiol. Spectr. 3. doi: 10.1128/microbiolspec. ve-0002-2014

Shao, C., and Hor, L. (2000). Metalloprotease is not essential for Vibrio vulnificus virulence in mice. Infect. Immun. 68, 3569-3573. doi: 10.1128/IAI.68.6.356 9-3573.2000

Sheahan, K.-L., Cordero, C. L., and Satchell, K. J. F. (2004). Identification of a domain within the multifunctional Vibrio cholerae RTX toxin that covalently cross-links actin. Proc. Natl. Acad. Sci. U.S.A. 101, 9798-9803. doi: 10.1073/pnas.0401104101

Shin, S. H., Shin, D. H., Ryu, P. Y., Chung, S. S., and Rhee, J. H. (2002). Proinflammatory cytokine profile in Vibrio vulnificus septicemic patients' sera. FEMS Immunol. Med. Microbiol. 33, 133-138. doi: 10.1111/j.1574-695X.2002.tb00582.x

Simpson, L. M., White, V. K., Zane, S. F., and Oliver, J. D. (1987). Correlation between virulence and colony morphology in Vibrio vulnificus. Infect. Immun. $55,269-272$.

Slungaard, A., and Key, N. S. (1994). Platelet factor 4 stimulates thrombomodulin protein C-activating cofactor activity: a structure-function analysis. J. Biol. Chem. 269, 25549-25556.

Stamm, L. V. (2010). Role of TLR4 in the host response to Vibrio vulnificus, an emerging pathogen. FEMS Immunol. Med. Microbiol. 58, 336-343. doi: 10.1111/j.1574-695X.2009.00643.x

Strom, M. S., and Paranjpye, R. N. (2000). Epidemiology and pathogenesis of Vibrio vulnificus. Microbes Infect. 2, 177-188. doi: 10.1016/S1286-4579(00)00270-7

Tison, D. L., Nishibuchi, M., Greenwood, J. D., and Seidler, R. J. (1982). Vibrio vulnificus biogroup 2: new biogroup pathogenic for eels. Appl. Environ. Microbiol. 44, 640-646.

Tisoncik, J. R., Korth, M. J., Simmons, C. P., Farrar, J., Martin, T. R., and Katze, M. G. (2012). Into the eye of the cytokine storm. Microbiol. Mol. Biol. Rev. 76, 16-32. doi: 10.1128/MMBR.05015-11

Valiente, E., Jiménez, N., Merino, S., Tomas, J. M., and Amaro, C. (2008a). Vibrio vulnificus biotype 2 serovar e gne but not galE is essential for lipopolysaccharide biosynthesis and virulence. Infect. Immun. 76, 1628-1638. doi: 10.1128/IAI.01393-07

Valiente, E., Lee, C. T., Lamas, J., Hor, L., and Amaro, C. (2008b). Role of the virulence plasmid pR99 and the metalloprotease Vvp in resistance of Vibrio vulnificus serovar E to eel innate immunity. Fish Shellfish Immunol. 24, 134-141. doi: 10.1016/j.fsi.2007.10.007

Wang, X., and Liu, Y. (2007). Regulation of innate immune response by MAP kinase phosphatase-1. Cell. Signal. 19, 1372-1382. doi: 10.1016/j.cellsig.2007. 03.013

Yanisch-Perron, C., Vieira, J., and Messing, J. (1985). Improved M13 phage cloning vectors and host strains: nucleotide sequences of the M13mpl8 and pUC19 vectors. Gene 33, 103-119. doi: 10.1016/0378-1119(85) 90120-9

Zhao, Q., Wang, X., Nelin, L. D., Yao, Y., Matta, R., Manson, M. E., et al. (2006). MAP kinase phosphatase 1 controls innate immune responses and suppresses endotoxic shock. J. Exp. Med. 203, 131-140. doi: 10.1084/jem.20051794

Conflict of Interest Statement: The authors declare that the research was conducted in the absence of any commercial or financial relationships that could be construed as a potential conflict of interest.

Copyright (c) 2017 Murciano, Lee, Fernández-Bravo, Hsieh, Fouz, Hor and Amaro. This is an open-access article distributed under the terms of the Creative Commons Attribution License (CC BY). The use, distribution or reproduction in other forums is permitted, provided the original author(s) or licensor are credited and that the original publication in this journal is cited, in accordance with accepted academic practice. No use, distribution or reproduction is permitted which does not comply with these terms. 